\title{
Spatial and species-level predictions of road mortality risk using trait data
}

Article

Accepted Version

Gonzalez-Suarez, M., Zanchetta Ferreira, F. and Grilo, C. (2018) Spatial and species-level predictions of road mortality risk using trait data. Global Ecology and Biogeography, 27 (9). pp. 1093-1105. ISSN 1466-8238 doi:

https://doi.org/10.1111/geb.12769 Available at https://centaur.reading.ac.uk/77162/

It is advisable to refer to the publisher's version if you intend to cite from the work. See Guidance on citing.

To link to this article DOI: http://dx.doi.org/10.1111/geb.12769

Publisher: Wiley

All outputs in CentAUR are protected by Intellectual Property Rights law, including copyright law. Copyright and IPR is retained by the creators or other copyright holders. Terms and conditions for use of this material are defined in the End User Agreement.

\section{www.reading.ac.uk/centaur}

\section{CentAUR}

Central Archive at the University of Reading 
Reading's research outputs online 


\section{Spatial and species-level predictions of road mortality risk using trait data}

3 Running title: Trait-based predictions of roadkill risk

4 Manuela González-Suárez ${ }^{1,3}$, Flávio Zanchetta Ferreira ${ }^{2}$, Clara Grilo $^{2}$

$5{ }^{1}$ Ecology and Evolutionary Biology, School of Biological Sciences, University of Reading,

6 Reading, RG6 6AS, UK

$7 \quad{ }^{2}$ Departamento de Biologia, Setor de Ecologia, Universidade Federal de Lavras, 37200-000,

8 Lavras, MG, Brazil

93 email: manuela.gonzalez@reading.ac.uk

11 Keywords: bird, Brazil, life-history, machine-learning models, mammal, random forest, road12 associated mortality, species' traits.

\section{Acknowledgments}

15 This study was part of the project "Road Macroecology: analysis tools to assess impacts on

16 biodiversity and landscape structure" funded by CNPq ( $\left.\mathrm{N}^{\circ} 401171 / 2014-0\right)$. F.Z.F. was

17 supported by a CAPES grant (N 32004010017P3) and CG by CNPq (AJT No 300021/2015-

18 1). We thank Michely Reis Coimbra for helping collecting trait data. Alex Bager, Anthony P.

19 Clevenger, Fernando Pinto, Andreas Kindel and two anonymous reviewers provided useful

20 comments on earlier versions of this manuscript.

\section{Biosketch}

23 Manuela González-Suárez is a lecturer at the University of Reading interested in

24 understanding how species' traits influence vulnerability to extinction and anthropogenic

25 threats from a local to a global scale. She has recently become interested in road ecology

26 working in Africa and South America. Flavio Zanchetta completed his MSc in road ecology

27 working to understand the factors that affect wildlife-vehicle collision risk in Portugal and

28 Brazil. Clara Grilo is currently a researcher at Federal University of Lavras, Brazil. Her

29 primary interest is applied ecological research namely examining role of human activities on

30 landscape and wildlife. In recent years, her research has focused on road ecology, mainly the

31 effects of roads on the relative abundance, behaviour, mortality risk and implications on

32 genetic structure and population viability of birds and mammals in Portugal, Spain and Brazil. 


\section{Abstract}

34 Aim: Wildlife-vehicle collisions are recognized as one of the major causes of mortality for

35 many species. Empirical estimates of road mortality show that some species are more likely to

36 be killed than others but to what extend this variation can be explained and predicted using

37 intrinsic species characteristics remains poorly understood. This study aims to identify general

38 macroecological patterns associated to road mortality and generate spatial and species-level

39 predictions of risks.

40 Location: Brazil

41 Time period: 2001-2014

42 Major taxa: Birds and mammals

43 Methods: We fitted trait-based random forest regression models (controlling for survey

44 characteristics) to explain 783 empirical road mortality rates from Brazil, representing 170

45 bird and 73 mammalian species. Fitted models were then used to make spatial and species-

46 level prediction of road mortality risk in Brazil considering 1775 birds and 623 mammals

47 which occur within the country's continental boundaries.

48 Results: Survey frequency and geographic location were key predictors of observed rates, but

49 mortality was also explained by species' body size, reproductive speed and ecological

50 specialization. Spatial predictions revealed high potential standardized (per km road)

51 mortality risk in Amazonia for birds and mammals, and additionally high risk in Southern

52 Brazil for mammals. Given the existing road network, these predictions mean more than 8

53 million birds and 2 million mammals could be killed per year in Brazilian roads. Furthermore,

54 predicted rates for all Brazilian endotherm uncovered potential vulnerability to road mortality

55 of several understudied species which are currently listed as threatened by the IUCN.

56 Conclusion: With a fast-expanding global road network, there is an urgent need to develop

57 improved approaches to assess and predict road-related impacts. This study illustrates the

58 potential of trait-based models as assessment tools to better understand correlates of

59 vulnerability to road mortality across species, and as predictive tools for difficult to sample or

60 understudied species and areas. 


\section{Introduction}

62 Roads are increasingly prevalent features in global landscapes (Laurance \& Balmford, 2013;

63 Ibisch, Hoffmann, Kreft, Pe'er, Kati, Biber-Freudenberger, ..., \& Selva, 2016) leading to

64 growing concerns about their impacts on wildlife (Alamgir, Campbell, loan, Goosem,

65 Clements, Mahmoud, \& Laurance, 2017). Wildlife-vehicle collisions are one of the most

66 visible road-related impacts (Coffin, 2007), which can reduce population abundance, limit dispersal, decrease genetic diversity, and ultimately threaten population viability (e.g., Fahrig \& Rytwinski, 2009; Borda-de-Água, Grilo, \& Pereira, 2014; Grilo C, Del Cerro, CentenoCuadros, Ramiro, Román, Molina-Vacas, Fernández-Aguilar, ..., \& Godoy, 2016). However, not all species appear to be equally affected by road-associated risks (Fahrig \& Rytwinski, 2009). Variation among species can reflect methodological issues: small species degrade faster and are less conspicuous, which can reduce their detectability once collision has occurred, leading to underestimated rates (Santos, Carvalho, \& Mira, 2011; Teixeira, Coelho, Esperandio, \& Kindel, 2013). Differences may also occur due to true variability in collision risk associated to local abundance, more common species being more likely to suffer high mortality rates (Ford \& Fahrig, 2007; Santos, Mira, Salgueiro, Costa, Medinas, \& Beja, 2016). However, detectability and abundance do not appear to be the only sources of variation. For example, the lowland tapir Tapirus terrestris and the crab-eating fox Cerdocyon thous have similar detectability and observed population densities in the Brazilian Pantanal region (0.4 ind $/ \mathrm{km}^{2}$ - Desbiez, Bodmer, \& Tomas, 2010), yet estimated mortality rates vary considerably (fox: 0.24 ind/km/year; tapir: 0.01 ind/km/year. Souza, Cunha, \& Markwith, 2014). An explanation is that variability in road mortality rates among species is also explained by species' traits related to ecological habits, behaviour, and life-history traits.

Species' traits can influence mortality risk via one or more of the processes that lead to collision. First, the probability of encountering roads can be influenced by how the animal moves on the landscape and acquires resources (Grilo, Molina-Vacas, Fernández-Aguilar, Rodríguez, Ramiro, Porto-Peter, \& Revilla, 2018). Previous studies have shown higher risks for passerine birds that forage on foliage or bark and inhabit woodlands (Santos et al., 2016), for herbivorous and omnivorous mammals (Barthelmess \& Brookes, 2010; Cook \&

90 Blumstein, 2013), and for more habitat generalist mammals (Núñez-Regueiro, Branch,

91 Fletcher Jr, Marás, Derlindati, \& Tálamo, 2015). Second, the probability of crossing an 92 encountered road may be affected by how the road is perceived and the animal's mobility 
(Jaeger, Bowman, Brennan, Fahrig, Bert, Bouchard, ..., Toschanowitz, 2005). For example, nocturnal species appear to have higher risk because low traffic volume at night may prevent roads from being perceived as a threat (Grilo, Sousa, Ascensão, Matos, Leitão, Pinheiro, ..., $\&$ Revilla 2012). Conversely, species exposed to regular hunting or poaching may be more aware of the human-associated risks often linked to roads, which lead them to avoid roads and thus reduce the risk of collision (Laurance, Croes, Tchignoumba, Lahm, Alonso, Lee, Campbell, \& Ondzeano, 2006). Finally, the probability of being hit if crossing can be influenced by the animals' agility, behaviour, and its visibility to drivers (Legagneux \& Ducatez, 2013). Collectively these previous results have shown that individual traits can be useful to understand road mortality risk, but to gain a comprehensive understanding and develop valuable predictive tools we need to simultaneously evaluate multiple ecological, behavioural and life-history traits for a diverse group of species.

Trait-based models are powerful tools commonly used in macroecological studies to assess the mechanisms underlying the response of species to impacts and predict risks for unstudied or difficult-to-detect organisms (González-Suárez, Gómez, \& Revilla, 2013; Bland,

108 Collen, Orme, \& Bielby, 2015). Here we used machine-learning trait-based models to assess

109 the role of a wide range of species' traits on estimated road mortality rates for bird and mammalian species in Brazil. We focused on birds and mammals because these are wellstudied groups that provide a suitable empirical dataset (e.g. Coelho, Kindel, \& Coelho, 2008). Brazil is also an interesting case study because in the last two decades economic and social growth has led to a $20 \%$ increase in the road network, increasing impacts on wildlife

114 (DNIT, 2015) and this growth is likely to continue and expand into regions of exceptional

115 biological diversity and global ecological importance like the Cerrado and the Amazon

116 (Hoorn, Wesselingh, TerSteege, Bermudez, Mora, Sevink, ..., Antonelli, 2010; Lahsen,

117 Bustamante \& Dalla-Nora, 2016). Therefore, there is an urgent need to better understand and 118 predict road risks within Brazil to guide infrastructure planning and mitigation measures,

119 including the protection of those species that are most susceptible to road impacts. To achieve 120 this goal we fitted trait-based models to predict road mortality rates for all Brazilian birds and 121 mammals including the many species for which roadkill estimates are not currently available

122 (unstudied or undetected organisms). These predictions allowed us to identify unstudied

123 species with high vulnerability to road-related mortality, and revealed areas where road 124 impact is likely high. Our study provides a first comprehensive evaluation of the key intrinsic 


\section{Methods}

130 Data

131 Empirical road mortality rates for birds and mammals were collected from unpublished

132 databases (made available by individual researchers contacted via the Lattes platform

133 http://lattes.cnpq.br), grey literature sources (technical reports, proceedings of scientific

134 conferences, MSc and $\mathrm{PhD}$ theses), and scientific papers from peer-reviewed journals.

135 Published sources were located using the following keywords in English and their translations to Portuguese: ("roadkills" OR "road mortality”) AND ("birds" OR "mammals" OR "vertebrates"). We considered only rates from areas of Brazil in which systematic surveys had been conducted at least once a week for a minimum period of three months to minimize the bias on roadkill rates among studies. From each study, road mortality rates per species were calculated as the number of individual carcasses detected standardized per kilometre of surveyed road per year (ind/km/year). Rates may be underestimated because not all carcasses persist equally in the pavement. In addition, in some studies not all carcases were identified or reported at the species level. The calculated rates were modified using a correction for carcass persistence estimated by Santos, Carvalho, \& Mira (2011) that aims to reduce bias from variable detection rates among species (see Appendix S1 in Supporting Information). Both corrected and uncorrected rates were tested to evaluate consistency of results. We present the corrected rates in the main text, but results did not change qualitatively when using uncorrected rates (see Appendix S2). We characterized the study location using the geographic coordinates of the surveyed road(s) midway point (Appendix S3, Fig. S3.1). Taxonomic names used by each study were matched to the current IUCN taxonomy (IUCN 2017). One mammalian species with empirical road mortality data (Guerlinguetus ingrami) was not recognized by the IUCN and was not considered in the analyses. Coendou spinosus was listed as two different species (Coendou villosus or Coendou spinosus) in separate studies but treated as one species in our analyses.

We identified Brazilian birds and mammals based on overlap of distribution range maps (IUCN 2017) with the continental Brazilian territory (based on the IUCN country boundary 
map). We used distribution range polygons classified as presence "Extant" or "Possible extant" and included all origins and seasonalities. These range polygons were also overlapped with a $1^{\circ} \times 1^{\circ}$ grid (equivalent to $\sim 110 \times 110 \mathrm{~km}$ near the equator) covering the continental Brazilian territory.

We considered 12 species' traits as potentially important to predict the vulnerability of species to road mortality and used published trait databases to find information on all Brazilian birds and mammals (see Table 1 for details).

\section{Data analysis}

We modelled empirical road mortality rates using random forest regression trees, a machine learning technique that uses bootstrapped data samples to generate multiple regression trees from which the importance of the predictors is defined (Breiman, 2001). Regression trees have high predictive accuracy and the capacity to deal with complexity in relationships including non-linearities and interactions (Cutler, Edwards, Beard, Cutler, Hess, Gibson, \& Lawler, 2007). Regression trees have also been show to offer comparable results to phylogenetic methods that explicitly account for the fact that related species may share similar traits due to shared evolutionary history (Bielby et al., 2009). While incorporating phylogenetic information into regression trees is not possible, to capture the potential importance of phylogeny we included taxonomic order (following the classification of the IUCN, 2017) as a predictor in our models.

Rates from birds and mammals were analysed separately to reflect the intrinsic differences between these groups. For each imputed version (15 per taxonomic group) we fitted a random forest model with 2000 trees using the randomForest procedure from the randomForest library (Liaw \& Wiener, 2002) in R version 3.4.1 (R Core Team 2017). Model predictors included traits (Table 1), taxonomic order, and the three survey related predictors for each study: survey interval (time between surveys in days), and latitude and longitude of the surveyed road(s) midway point.

Trait data were not available for all species (data limitations are common in comparative studies, see González-Suárez, Lucas, \& Revilla, 2012). To avoid excluding observations, which can lead to biases, we estimated missing values for each taxonomic group using nonparametric imputation based on random forest regression trees (Stekhoven \& Bühlmann, 2012). Since this imputation approach results in slightly different values each time 
189 it is run, we imputed and analysed 15 datasets for each taxonomic group to capture

190 uncertainty in the imputation process and assess sensibility of results to that uncertainty. To

191 facilitate reproducibility and encourage open science the code (R script) and data used in this

192 study will be available at https://dx.doi.org/ 10.6084/m9.figshare.6237608 on 9 November

1932018.

194 We assessed overall model performance using the total variance explained. We also

195 calculated the importance of each variable by permuting all observed values within each

196 variable across observations and evaluating the effect on model performance (changes in

197 variance explained). The permutation of important variables decreases significantly the model

198 performance whereas the permutation of less important variables should have little effect on

199 the model performance.

200 Fitted models were subsequently used to generate predicted values for each Brazilian

201 species in each of its occupied $1^{\circ}$ x $1^{\circ}$ grid cells, representing a hypothetical systematic survey

202 across all Brazil (cells treated as studies sites). Geographic coordinates were defined as those

203 of the grid cell centroid. The survey interval was set to the observed median value (3.5 days

204 between surveys for both birds and mammals). Different survey intervals did not qualitatively

205 affect results (Appendix 3 figure S3.2). We used the median prediction from the 15 models

206 based on the different imputed datasets for each cell and species combination. Predicted risk

207 for each species (species-level predictions) was then calculated as the median of the predicted

208 rates over all its occupied grid cells; thus, reflecting intrinsic vulnerabilities and spatial risks

209 within the species' distribution range. Spatial predictions were generated by aggregating

210 predicted values for each grid cell, thus, summarizing risk associated to geographic location

211 and to the intrinsic vulnerabilities of co-occurring species. We calculated a standardized risk

212 based on ind/km/year, and a predicted total risk (ind/year) obtained by multiplying the

213 standardized risk by the total kilometres of paved road within each grid cell. Road network

214 data were obtained from the Openstreetmap available at https://www.openstreetmap.org. As

215 there is limited knowledge on the responses of the different species to roads, our approach

216 assumes no specific road avoidance.

\section{Results}

219 We located 38 studies that reported road mortality rates in different areas of Brazil and met

220 our criteria of minimum frequency and period of survey (Figure S3.1). From these studies we 
obtained 417 mortality rates for 170 bird species, and 366 road mortality rates for 73 mammal species. Based on current distribution range maps we identified 1831 birds and 623 mammals as present in Brazil. We made predictions for all mammals, but had to exclude 56 bird species classified in taxonomic orders not represented in our empirical dataset (predictions cannot be made for new levels in a categorical variable). All data are available on (to be deposited on online repository upon acceptance, and made available as supplementary files for review).

Some species were reported by multiple studies, for example the smooth-billed ani Crotophaga ani was the most frequently detected bird (16 studies), while the crab-eating fox was the most frequently reported mammal (32 studies). However, many species were only observed in one study (90 bird species and 26 mammals). Observed (corrected) road mortality rates ranged from 0.001 to $7.61 \mathrm{ind} / \mathrm{km} /$ year for birds (highest rate was observed for Crotophaga ani). For mammals rates ranged from 0.0007 to $18.52 \mathrm{ind} / \mathrm{km} /$ year (highest rate was reported for the capybara Hydrochoerus hydrochaeris).

Fitted models explained $61.7 \%$ of the observed variance in road mortality rates for birds

235 (median value, range across imputed datasets 61.1-62.4\%) and 51.8\% for mammals (range

$23651.2-52.4 \%$ ). As expected survey predictors were important in both groups (Fig. 1). In

237 particular, survey interval was the most important predictor with intervals of 1-2 day

238 generally associated with higher estimates both for birds and mammals (Figs. 2 and 3).

239 Geographic location also explained observed road mortality rates (Fig. 1) with partial 240 dependence plots showing higher rates associated to western locations for both birds and mammals, but contrasting patterns for latitude, with locations closer to the equator associated

242 with higher risk in birds but with lower risk in mammals (Figs. 2 and 3). Taxonomic order

243 was an important predictor for birds with higher rates found among cuckoos and anis

244 (Cuculiformes, eight species) and flightless birds (Cariamiformes, one species;

245 Struthioniformes, four species). Order was also important for mammals, with higher rates 246 among anteaters and sloths (Pilosa, 6 species) and armadillos (Cingulata, six species).

247 The analyses also revealed several species' traits as predictors of road mortality rates in 248 both birds and mammals with high consistency among models based on the different imputed 249 datasets (Fig. 1). Partial dependence plots show higher road mortality rates in birds associated 250 to larger body mass ( $>2 \mathrm{~kg}$ ), earlier maturity ages, shorter lifespans, ground foraging 251 behaviour, and habitat and diet generalism (Fig. 2). For mammals, higher rates were 
associated with scavenging behaviour, early maturity, smaller home range sizes, intermediate body masses (3-50 kg), and habitat generalism (Fig. 3).

Model predictions matched empirical data well for mammals, but showed a tendency to overestimate low values for birds (Fig. S3.3). Both observed and predicted rates showed considerable within-species variation. Overall, median observed and predicted road mortality rates per species were lower among species with more threatened conservation status as defined by the global IUCN Red List status (Fig. S3.4).

Median predicted rates for all Brazilian species ranged from 0.02 to $0.37 \mathrm{ind} / \mathrm{km} / \mathrm{year}$ for birds and from 0.02 to $1.08 \mathrm{ind} / \mathrm{km} /$ year for mammals. Among species without empirical data, the blue-black grassquit Volatinia jacarina and Reig's grass mouse Akodon reigi had the highest predicted rates ( 0.37 and 1.08 respectively, data available at - online repository). High rates were also predicted for several unstudied species of conservation concern, including the white-lined antbird Myrmoborus lophotes and the rufous-fronted antthrush Formicarius rufifrons, both birds listed as Near Threatened by the IUCN Red List (predicted median rates of 0.30 and $0.28 \mathrm{ind} / \mathrm{km} /$ year, respectively), and the greater Wilfred's mouse Wilfredomys oenax (Endangered status, predicted median rates of $0.93 \mathrm{ind} / \mathrm{km} / \mathrm{year}$ ) and the Lami tucotuco Ctenomys lami (Vulnerable status, predicted median rates of $0.44 \mathrm{ind} / \mathrm{km} / \mathrm{year}$ ).

The map of standardized predicted spatial risk (the sum of all predicted mortalities per kilometre of road per year for species co-occurring in a given grid cell) showed high expected roadkill rates in the western Amazon region for both birds and mammals, and also high mammalian rates in the Pampas region (southern Brazil), with the lowest values generally

273 found in eastern Brazil (Fig. 4a, b). These patterns were consistent when representing median

274 standardized predicted risk, the rates expected for an average species in each cell per

275 kilometre of road (Fig. S3.5). Areas with high predicted risk generally also showed high

276 variability among species (high standard deviation. Fig S3.5), reflecting differences in

277 intrinsic vulnerabilities of the local fauna. These spatial standardized risk patterns did not 278 solely reflect species richness. For example, the highest road mortality rates for mammals were predicted in southern Brazil where mammalian richness is lowest (Fig. 4e, f).

When considering the existing road network to estimate total mortality (number of mortalities per year in each grid cell, Fig. 4c, d), the patterns, as expected, changed, and

282 revealed higher total predicted risk in coastal areas where most roads are found (Fig. S3.6).

283 However, total mortality did not exclusively reflect existing roads. For example, risk was high 
in Western areas (Mato Grosso and Rondonia) where there are relatively few roads, and relatively low in the Northeast region where road density is high. Worryingly, in some areas total risk was very high with expected rates of over 96,000 individual birds and over 53,000 individual mammals killed per year in some $1^{\circ} \times 1^{\circ}$ areas. Adding all predicted rates across the country our results suggest that as many as $8,351,120$ birds and 2,225,101 mammals could be killed per year in Brazilian roads. Considering potential impacts of additional planned paved roads (Fig. 3.7) we find increased risk in the Amazon, which we identify as a sensitive area (with high standardized and median risk rates).

Mapping predicted rates only for threatened species we found a slightly different spatial pattern with highest risk found in the eastern Amazon (Fig S3.8). The predicted total risk suggests as many as 179,601 threatened birds and 73,031 threatened mammals could be killed per year in Brazilian roads.

\section{Discussion}

Our results provide evidence that road-associated mortality risk is not randomly distributed among species and can be partly explained by ecological, behavioural and life-history traits in avian and mammalian species. Previous studies explored the role of individual traits (e.g. Ford \& Fahrig, 2007; Cook \& Blumstein, 2013), but our results reveal that road mortality is associated to a combination of multiple predictors that reflect diverse characteristics of the studied species. Although analyses were conducted separately, we found that several traits explained vulnerability to traffic for both bird and mammal species suggesting generalized intrinsic sources of risk for endotherms, for example associated with body size. Our study also identified distinct sources of vulnerability, which highlight idiosyncrasies of the studied species and/or distinct mechanisms associated with vulnerability for birds and mammals. In addition, road mortality also varied among taxonomic groups, potentially reflecting untested characteristics. For example, for mammals we found higher rates among relatively slow moving species like armadillos and sloths, while for birds flightless groups exhibited higher rates. As expected survey-related variables were also important predictors of risk. Although we used a correction factor, survey interval remained a key predictor for both groups. Our results suggest that 1-2 days intervals between surveys may be optimal to assess risks for these species (those intervals were associated with the higher rates - see also Santos et al., 2011). Survey location was also important for both birds and mammals, with higher predicted 
risk towards the west in both groups but contrasting latitudinal gradients that identified distinct risk regions within Brazil for birds and mammals.

We observed that species with weights above 2-3 $\mathrm{kg}$ had higher risk of being roadkilled, although for mammals the risk decreased again for species above $\sim 50 \mathrm{~kg}$. Generally, larger species tend to be more mobile (Sutherland, Harestad, Price, \& Lertzman, 2000), which increases the probability of encountering and crossing roads. However, for the largest mammals, collision risk may be reduced due to earlier detection by drivers, which provides more time for response, and also due to more active avoidance responses by drivers seeking to prevent potentially dangerous collisions. Lower risk among smaller species could be partly explained by variation in detectability during surveys (methodological limitations). Smaller species are more difficult to see, and degrade faster, and this could result in potentially underestimated mortality rates. However, we actually found some increases in risk predicted for some small species, suggesting detectability during surveys does not fully explain this pattern. A previous study also reported a trend for higher mortality rates in smaller birds based on species <1.2 kg (Santos et al., 2016).

Our findings also suggest generalists (those with wider habitat and diet breadths) have higher mortality rates than specialists (although for mammals diet specialization was not clearly related to road mortality risk). However, contrary to previous studies, we did not find an effect of trophic level (Ford \& Fahrig, 2007; Cook \& Blumstein, 2013). It is possible this difference occurs because those previous studies did not consider diet specialization. By exploring both variables we show that the degree of specialization may be more informative to predict roadkill likelihood than trophic level, at least for birds. In general, specialist species may be less likely to approach and cross roads if these are perceived as unsuitable environments. Previous studies have shown that species that are reluctant to cross open grounds avoid crossing roads due to low availability of cover, and therefore have lower likelihood of being roadkilled (Develey \& Stouffer, 2001; Rytwinski \& Fahrig, 2012).

Moreover, the high availability of resources and refuges in road verges can attract habitat and diet generalist species to roads and increase their risk of being hit by passing vehicles (RuizCapillas, Mata, \& Malo, 2012; Barrientos \& Bolonio, 2009). Among the resources that may be available near roads are roadkill carcasses, which attract scavengers, potentially increasing their collision risk. Although we found scavenging behaviour of mammals considerably increased mortality rates, there was no clear association for birds. A previous study by Cook 
\& Blumstein (2013) reported no effect of scavenging behaviour for either group. These contrasting results may be due to individual responses to traffic and risk perception (Jacobson, Bliss-Ketchum, De Rivera, \& Smith, 2016) and also be influenced by road-related features including sinuosity and traffic intensity (Grilo, Ascensão, Santos-Reis, \& Bissonette, 2011). Population-level processes can also influence risk with locally abundant species being more likely to have higher mortality rates. Although we did not have abundance estimates for the studied areas, higher local abundance is often associated with faster reproductive rates (e.g., earlier maturity ages) which we found were associated with higher risk of collision in both birds and mammals. However, while consistent with predicted patterns, we note that many estimates of maturity age were imputed, particularly for bird species, thus, support should be interpreted with caution. Future studies would benefit from conducting both roadkill and abundance surveys in the same areas to better understand road-associated risks.

Besides contributing to our understanding of the general drivers of road-associated mortality, our analyses show trait-based models can be used as predictive tools for conservation assessment and management of road-related impacts. Our model predicted high roadkill rates for several species of conservation concern for which empirical estimates are not currently available. Empirical estimates may be unavailable for different reasons: 1) species only inhabit poorly sampled areas (e.g., Amazon); 2) species occur in sampled areas but avoid modified habitats including roads; and 3) species are not detected (e.g., small size bias) or are not correctly identified during surveys due to taxonomic uncertainty or cryptic characteristics. A recommendation that emerges from our study is the need for targeted survey efforts for species identified as potentially susceptible here so their true risk can be quantified and if needed adequate management and mitigation actions can be implemented.

Our results also generate spatial predictions of road mortality risks, which highlight the apparent high vulnerability of Amazonian species (higher risk per kilometre of road). Although mortality rates in this area are likely to be relatively small due to low road density, this region has high biodiversity and our analyses suggest road infrastructure development could have severe impacts on many species. Considering the existing road network, as expected, we found higher total risk in areas with higher road density. However, median risk per species was not always high in areas, like Southern Brazil, with many threatened species and high road densities, perhaps reflecting former population depression due to road mortality (Teixeira, Kindel, Hartz, Mitchell, \& Fahrig, 2017). Worryingly, our results suggest that more 
than 8 million individual birds (nearly 180,000 from species threatened by extinction) and more than 2 million mammals (over 72,000 from threatened species) may be killed each year in existing Brazilian roads. These high values are predicted despite the fact that Brazil has a relatively high number of roadless areas (Ibisch, Hoffmann, Kreft, Pe'er, Kati, BiberFreudenberger, ..., \& Selva, 2016). Furthermore, our rates may be underestimated because we do not consider unpaved roads. We also do not account for other indirect road impacts, such as changes in spatial distribution due to road avoidance (Torres, Jaeger \& Alonso, 2016), which can reduce roadkill but may in turn impact population viability in other ways. Future road development is also likely to result in increased risk, particularly in areas we identified as sensitive (with intrinsically vulnerable species), like the Amazon. These results provide a first overview of risk revealing potentially vulnerable species and areas. However, localized and refined spatial predictions (accounting for unpaved roads and traffic levels) would be useful to further describe areas in which road development is likely to have widespread impacts on the local fauna, as well as areas in which mitigation measured would be most valuable.

While our analyses offer useful insights, there are also limitations of the available data. First, missing trait data is a common problem in comparative studies (González-Suárez et al., 2012). Data imputation methods may be helpful but some limitations (e.g. handling variable correlation) need consideration (Penone, Davidson, Shoemaker, Marco, Rondinini, Brooks, ..., Costa, 2014). Also imputation of large proportions of the dataset incorporate uncertainty in results, this can be quantified as done here, but results should still be interpreted with caution. In addition, to missing trait data, empirical estimates of road mortality were also not available for all species or areas. Instead, these data reflect a non-random subset of species and locations, associated to biases in research effort and methodological issues. In fact, these biases may explain the relatively abrupt geographic changes in our spatial predictions, particularly for birds. Variation in detectability during surveys is a recurrent problem in road surveys. Carcasses from small species may disappear from roads in less than 24 hours (Teixeira et al., 2013). Carcasses in hot, humid areas, and those with high traffic levels may also disappear faster. We applied corrections to the observed road mortality rates, but our results were qualitatively the same when using uncorrected rates (Appendix 1) contrary to what Santos et al. (2011) found in their study. The criteria we adopted to only include studies with a 7-day minimum survey interval may have contributed to reduce differences; intervals 
412 of one week or shorter have been found to significantly reduce bias for medium- and large-

413 sized birds and mammals (Bager \& Rosa, 2011). Ultimately, data limitations and biases can

414 only be effectively addressed with additional research efforts. In the meantime, studies using

415 available data should consider uncertainty in results, explore correction methods, and interpret

416 findings with caution.

417 Overall, our results contribute to a better understanding of the biological drivers that

418 make species vulnerable to road traffic collisions. Previous studies have largely focused on

419 the importance of road characteristics (e.g. traffic, size, and design) and landscape features

420 (e.g. vegetation type, and degree of fragmentation; Saeki \& Macdonald, 2004; Grilo,

421 Bissonette, \& Santos-Reis, 2009). However, our study shows that using available knowledge

422 on species traits and macroecological approaches can contribute to better evaluate risks and

423 offer insights into species and spatial level risks. Obtained predictions can guide future survey

424 efforts, pointing to poorly sampled areas with potentially susceptible species, and may also be

425 used to plan conservation strategies, road development, and mitigation measures. These

426 predictions also offer insights into the magnitude of the threat imposed by roads, with

427 potentially millions of individual birds and mammals being killed each year within one

428 country.

\section{$430 \quad$ Literature Cited}

431 Alamgir, M., Campbell, M. J., Sloan, S., Goosem, M., Clements, G., Mahmoud, M. I., \&

432 Laurance, W.F. (2017). Economic, socio-political and environmental risks of road

433 development in the tropics. Current Biology, 27, R1130-R1140.

435 Bager, A., \& Rosa, C. A. (2011). Influence of sampling effort on the estimated richness of 436 roadkilled vertebrate wildlife. Environmental Management, 47, 851-858.

438 Barrientos, R., \& Bolonio, L. (2009). The presence of rabbits adjacent to roads increases

439 polecat road mortality. Biodiversity and Conservation, 18, 405-418.

441 Barthelmess, E. L., \& Brooks M. S. (2010). The influence of body-size and diet on roadkill

442 trends in mammals. Biodiversity and Conservation, 19,1611-1629. 
444 Bielby, J., Cardillo, M., Cooper, N., \& Purvis, A. (2010). Modelling extinction risk in

445 multispecies data sets: phylogenetically independent contrasts versus decision trees.

446 Biodiversity and Conservation, 19, 113-127.

448 Bland, L. M., Collen, B., Orme, C. D. L. \& Bielby, J. (2015), Predicting the conservation

449 status of data-deficient species. Conservation Biology, 29, 250-259.

451 Borda-de-Água L., Grilo C., \& Pereira, H. M. (2014). Modeling the impact of road mortality 452 on barn owl (Tyto alba) populations using age-structured models. Ecological Modelling, 276, $45329-37$.

455 Breiman, L. (2001). Random Forests. Machine Learning 45, 5-32.

Coelho, I. P., Kindel, A., \& Coelho, A. V. P. (2008). Roadkills of vertebrate species on two

Coffin, AW. (2007). From roadkill to road ecology: A review of the ecological effects of roads. Journal of Transport Geography, 15, 396-406.

Cook, T. C., \& Blumsteim, D. T. (2013). The omnivore's dilema: diet explains variation in (2007). Random forest for classification in ecology. Ecology, 88: 2783-2792.

Desbiez, A. L. J., Bodmer, R. E., \& Tomas, W. M. (2010). Mamalian densities in a

473 Develey, P. F., \& Stouffer, P. C. (2001). Effects of roads on movements by understory birds

474 in mixed-species flocks in Central Amazonian Brazil. Conservation Biology, 15, 1416-1422. 
476 Dinerstein, E., Olson, D., Joshi, A., Vynne, C., Burgess, N. D., Wikramanayake, E., ...

477 Saleem, M. (2017). An ecoregion-based approach to protecting half the terrestrial

478 realm. Bioscience, 67, 534-545.

479

480 DNIT (Departamento Nacional de Infraestrutura de Transportes) (2015). Sistema nacional de 481 viação. Brasília, DF, Brasil.

483 Fahrig, L., \& Rytwinski, T. (2009). Effects of roads on animal abundance: an empirical 484 review and synthesis. Ecology and Society, 14, 21.

486 Ford, A. T., \& Fahrig, L. (2007). Diet and body size of North American mammal road 487 mortalities. Transportation Research Part D, 12, 498-503.

489 González-Suárez, M., Lucas, P. M., \& Revilla, E. (2012). Biases in comparative analyses of 490 extinction risk: mind the gap. Journal of Animal Ecology, 81, 1211-1222.

492 González-Suárez, M., Gómez, A., \& Revilla, E. (2013). Which intrinsic traits predict

493 vulnerability to extinction depends on the actual threatening processes. Ecosphere, 4, 76.

495 Grilo, C., Bissonette, J. A., \& Santos-Reis, M. (2009). Spatial-temporal patterns in

496 Mediterranean carnivore road casualties: Consequences for mitigation. Biological

497 Conservation, 142, 301-313.

499 Grilo, C., Ascensão, F., Santos-Reis, M., \& Bissonette, J. A. (2011). Do well-connected

500 landscapes promote road-related mortality? European Journal of Wildlife Research, 57, 707501716.

503 Grilo, C., Sousa J., Ascensão, F., Matos, H., Leitão, I., Pinheiro, P., .. \& Revilla, E. (2012).

504 Individual spatial responses towards roads: implications for road mortality risk. PLoS ONE 7, 5059. 
G., ...Godoy, J. (2016). Heterogeneous road networks have no apparent effect on the genetic

Grilo, C., Molina-Vacas, G., Fernández-Aguilar, X., Rodríguez, J., Ramiro, V., Porto-Peter, F.,... Revilla, E. (2018). Species-specific movement traits and specialization determine the spatial responses of small mammals towards roads. Landscape and Urban Planning, 169, 199-207.

Hoorn, C., Wesselingh, F. P., Ter Steege, H., Bermudez, M. A., Mora, A., Sevink, J., ... Antonelli, A. (2010). Amazonia through time: Andean uplift, climate change, landscape evolution and biodiversity. Science, 330, 927-931.

Ibisch, P. L., Hoffmann, M. T., Kreft, S., Pe’er, G., Kati, V., Biber-Freudenberger, L., ... \&

IUCN (2017). The IUCN Red List of threatened species. <http://www.iucnredlist.org>.

Downloaded on 11 October 2017.

Jacobson, S. L., Bliss-Ketchum, L. L., De Rivera, C. E., \& Smith, W. P. (2016). A behaviorbased framework for assessing barrier effects to wildlife from vehicle traffic

Jaeger, J. A. G., Bowman, J., Brennan, J., Fahrig, L., Bert, D., Bouchard., J., ...Toschanowitz K. T. (2005). Predicting when animal populations are at risk from roads: an interactive model of road avoidance behaviour. Ecological Modelling, 185, 2, 329-348. recently extinct mammals. Ecology, 90, 2648-2648. 
Lahsen, M., Bustamante, M. Mc., \& Dalla-Nora, E. L. (2016). Undervaluing and overexploiting the Brazilian Cerrado at our peril. Environment: Science and Policy for Sustainable Development, 58, 6.

Laurance, W. F., Croes, B. M., Tchignoumba, L., Lahm, S. A., Alonso, A., Lee, M. E.,

Campbell, P., \& Ondzeano, C. (2006). Impacts of roads and hunting on central African rainforest mammals. Conservation Biology, 20, 1251-1261.

Laurance, W. F., \& Balmford A. (2013). Land use: a global map for road building. Nature, 495, 308-309.

Legagneux, P., \& Ducatez, S. (2013). European birds adjust their flight initiation distance to road speed limits. Biology Letters, 9(5), 20130417.

Liaw, A., \& Wiener, M. (2012). Classification and regression by random forest. $R$ News, 2 , $18-22$.

Lindsted, S. L., Miller, B. J., \& Buskirk, S. W. (1986). Home range, time and body size in mammals. Ecology, 67, 413-418.

Myhrvold, N. P., Baldridge, E., Chan, B., Sivam, D., Freeman, D. L., \& Ernest, S. K. M. (2015). An amniote life-history database to perform comparative analyses with birds, mammals, and reptiles. Ecological Archives, 96, 3109-3109.

Núñez-Regueiro, M. M., Branch, L., Fletcher, Jr R. J., Marás, G. A., Derlindati, E., \& Tálamo, A. (2015). Spatial patterns of mammal occurrence in forest strips surrounded by agricultural crops of the Chaco region, Argentina. Biological Conservation, 187,19-26.

Paglia, A.P., Fonseca, G. A. B., Rylands, A. B., Herrmann, G., Aguiar, L. M. S., Chiarello, A. G., ..., Patton, J. L. (2012). Annotated checklist of Brazilian mammals $2^{\text {nd }}$ Edition. Occasional

\section{Papers in Conservation Biology, 6, 1-76.}


570 Penone, C., Davidson, A. D., Shoemaker, K. T., Marco, M. D., Rondinini, C., Brooks, T. M., ..., 571 \& Costa, G. C. (2014). Imputation of missing data in life-history traits dataset: which approach 572 performs the best? Methods in Ecology and Evolution, 5, 961-970.

574 R Core Team (2017). R: A language and environment for statistical computing. R Foundation 575 for Statistical Computing, Vienna, Austria. URL https://www.R-project.org/.

577 Ruiz-Capillas, P., Mata, C., \& Malo, J. E. (2012). Road verges are refuges for small mammal 578 populations in extensively managed Mediterranean landscapes. Biological Conservation, 158, 579 223-229.

Rytwinski, T., \& Fahrig, L. (2012). Do species life history traits explain population responses to roads? A meta-analysis. Biological Conservation, 147, 87-98.

584 Saeki, M., \& Macdonald, D. W. (2004). The effects of traffic on the raccoon dog (Nyctereutes

procyonides viverrinus) and other mammals in Japan. Biological Conservation, 118, 559-571.

Santos, S. M., Carvalho, F., \& Mira, A. (2011). How long do the dead survive on the road? 6, 9.

Santos, S. M., Mira, A., Salgueiro, P. A., Costa, P., Medinas, D., \& Beja, P. (2016). Avian

trait-mediated vulnerability to road traffic collisions. Biological Conservation, 200, 122-130.

594 Souza, J. C., Cunha, V. P., \& Markwith, S. H. (2014). Spatiotemporal variation in human595 wildlife conflicts along highway BR-262 in the Brazilian Pantanal. Wetlands Ecology and 596 Management, 23, 227-239.

598 Stekhoven, D. J., \& Bühlmann, P. (2012). MissForest-non-parametric missing value imputation for mixed-type data. Bioinformatics, 28, 112-118. 
601 Sutherland, G. D. , Harestad A. S., Price K., \& Lertzman K. P. (2000). Scaling of natal

602 dispersal distances in terrestrial birds and mammals. Conservation Ecology, 4, 16.

603

604 Teixeira, F. Z., Coelho, A. V. P., Esperandio, I. B., \& Kindel, A. (2013). Vertebrate road

605 mortality estimates: Effects of sampling methods and carcass removal. Biological

606 Conservation, 157, 317-323.

607

608 Teixeira, F. Z., Kindel, A., Hartz, S. M., Mitchell, S., \& Fahrig, L. (2017). When roadkill

609 hotspots do not indicate the best sites for roadkill mitigation. Journal of Applied Ecology, 54,

610 1544-1551.

611

612 Torres, A., Jaeger, J. A., \& Alonso, J. C. (2016). Assessing large-scale wildlife responses to

613 human infrastructure development. Proceedings of the National Academy of Sciences of the

614 United States of America, 113, 8472-8477.

615

616 Wilman, H., Belmaker, J., Simpson, J., de la Rosa, C., Rivadeneira, M. M., \& Jetz, W. (2014).

617 EltonTraits 1.0: Species-level foraging attributes of the world's birds and mammals.

618 Ecological Archives, 95, 2027-2027.

619

620 Data accessibility

621 The R scripts and full database including available empirical road mortality rates, trait

622 descriptors, and predicted rates for all Brazilian birds and mammals will be available at

623 https://dx.doi.org/ 10.6084/m9.figshare.6237608 on 9 November 2018. 

Brazilian birds and mammals in this study. Total species considered for birds data $\mathrm{N}_{\text {all }}=1831$, birds with empirical roadkill rates $\mathrm{N}_{\mathrm{RK}}=170$, total mammalian species $\mathrm{N}_{\mathrm{all}}=623$, and mammals with empirical roadkill rates $\mathrm{N}_{\mathrm{RK}}=73$. Home range and sociality were only considered for mammals.

\begin{tabular}{|c|c|c|c|c|c|c|}
\hline \multirow[t]{2}{*}{ Trait } & \multirow[t]{2}{*}{ Definition and hypothesis } & \multirow[t]{2}{*}{ Data source } & \multicolumn{2}{|c|}{ Birds } & \multicolumn{2}{|c|}{ Mammals } \\
\hline & & & $\mathrm{N}_{\text {all }}$ & $\mathrm{N}_{\mathrm{RK}}$ & $\mathrm{N}_{\text {all }}$ & $\mathrm{N}_{\mathrm{RK}}$ \\
\hline Diet breadth & $\begin{array}{l}\text { Total number of } 10 \text { possible dietary categories consumed by each } \\
\text { species. } \\
\text { Diet generalist are more likely to use resources on road verges and } \\
\text { thus, approach roads leading to higher roadkill rates. }\end{array}$ & Wilman et al., 2014 & 1527 & 153 & 454 & 70 \\
\hline $\begin{array}{l}\text { Scavenger } \\
\text { behaviour }\end{array}$ & $\begin{array}{l}\text { Binary descriptor to identify species with diet consisting of } \geq 10 \% \\
\text { carrion. } \\
\text { Scavengers can forage on roadkill, and thus will spend time on } \\
\text { and near roads leading to higher roadkill rates. }\end{array}$ & Wilman et al., 2014 & 1700 & 168 & 585 & 72 \\
\hline Trophic level & $\begin{array}{l}\text { Trophic level described as: Herbivore ( }>80 \% \text { plant diet), } \\
\text { Carnivore ( }>80 \% \text { animal diet), or Omnivore ( }<80 \% \text { animal or } \\
\text { plant diet). We used } 80 \% \text { thresholds as some diet data may } \\
\text { include accidentally ingested material. }\end{array}$ & Wilman et al., 2014 & 1700 & 168 & 585 & 72 \\
\hline
\end{tabular}


Herbivores are more likely to utilize road verges, where

vegetation can benefit from run-off, leading to higher roadkill

rates.

\begin{tabular}{|c|c|c|c|c|c|c|}
\hline $\begin{array}{l}\text { Habitat } \\
\text { breadth }\end{array}$ & $\begin{array}{l}\text { Total number of ecoregions within Brazil overlapping the current } \\
\text { geographic range area of each species. } \\
\text { Habitat specialists are likely to avoid novel environments like } \\
\text { roads, leading to reduced roadkill rates. }\end{array}$ & Dinerstein et al., 2017 & 1831 & 170 & 544 & 70 \\
\hline $\begin{array}{l}\text { Ground } \\
\text { foraging }\end{array}$ & $\begin{array}{l}\text { Prevalence of foraging on ground estimated as percentage of use } \\
\text { of that substrate for birds. For mammals a categorical variable } \\
\text { describing species classified as "ground foragers". } \\
\text { Species that forage in arboreal or aerial environments are less } \\
\text { likely to be on roads, leading to reduced roadkill rates. }\end{array}$ & Wilman et al. 2014 & 1646 & 167 & 623 & 73 \\
\hline Activity cycle & $\begin{array}{l}\text { The main period a species is active defined as: nocturnal, diurnal } \\
\text { or other. } \\
\text { Nocturnal species are active at times with less traffic (which can } \\
\text { reduce their perception of risk) and also when visibility is limited } \\
\text { for drivers (affecting collision avoidance behaviours), both } \\
\text { mechanisms can lead to higher roadkill rates. }\end{array}$ & $\begin{array}{l}\text { Jones et al., 2009; } \\
\text { Wilman et al. } 2014\end{array}$ & 1700 & 168 & 585 & 72 \\
\hline
\end{tabular}




\begin{tabular}{|c|c|c|c|c|c|c|}
\hline Exploitation & $\begin{array}{l}\text { Binary descriptor to identify species classified as at risk from } \\
\text { direct exploitation based on the IUCN (species classified as } \\
\text { affected by categories } 5.1 \text { and/or } 5.4 \text { ). } \\
\text { Hunted species are more likely to perceive roads as risks and } \\
\text { avoid them, leading to reduced roadkill rates. }\end{array}$ & $\begin{array}{l}\text { IUCN Threats } \\
\text { Classification Schemes, } \\
\text { category } 5.1 \text { (Version } \\
\text { 3.2). }\end{array}$ & 1643 & 166 & 617 & 73 \\
\hline Body mass & $\begin{array}{l}\text { Average body mass in grams of an adult individual. Median } \\
\text { values per species based on all available sources. } \\
\text { Large species are generally more mobile which could increase } \\
\text { roadkill rates. }\end{array}$ & $\begin{array}{l}\text { Jones et al., 2009, Paglia } \\
\text { et al., 2012, Wilman et al. } \\
2014 \text {, }\end{array}$ & 1664 & 170 & 546 & 72 \\
\hline Home range & $\begin{array}{l}\text { Average home range size in } \mathrm{km}^{2} \text {. } \\
\text { Species with wider home ranges are more likely to overlap with } \\
\text { roads, leading to increased roadkill rates. }\end{array}$ & Jones et al. 2009 & $N A$ & $N A$ & 85 & 30 \\
\hline Lifespan & $\begin{array}{l}\text { The maximum recorded age of an individual of the species in } \\
\text { days. Median values per species based on all available sources. } \\
\text { Species with longer lifespans may be more likely to learn about } \\
\text { road risks, leading to reduced roadkill rates. }\end{array}$ & $\begin{array}{l}\text { Jones et al., 2009; } \\
\text { Myhrvold et al., } 2015\end{array}$ & 230 & 36 & 254 & 68 \\
\hline Maturity age & $\begin{array}{l}\text { Average age in years at which individuals reach sexual maturity. } \\
\text { Median values per species based on all available sources. }\end{array}$ & $\begin{array}{l}\text { Jones et al., 2009; } \\
\text { Myhrvold et al., } 2015\end{array}$ & 177 & 30 & 197 & 50 \\
\hline
\end{tabular}


Species with delayed maturation are more likely to prioritize

survival, which can lead to greater perception of risk from roads

and reduced roadkill rates.

Sociality Binary descriptor to identify species in which individual spend

Jones et al., 2009

$N A$

$N A$

most of their lives in a group. Defined as groups size $=1$ for

solitary.

Social species can benefit from collective vigilance and learning

experienced that can reduce roadkill rates. 
629 Figures and their legends

(a)

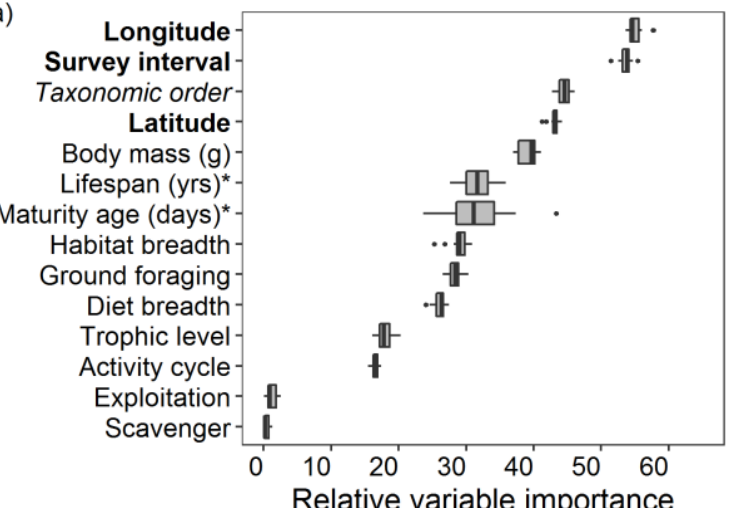

(b)

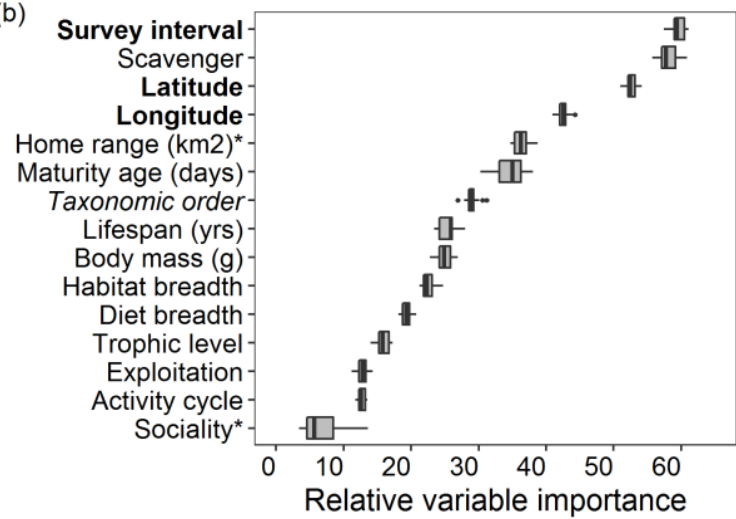

631 Figure 1. Relative importance of predictors associated with empirical road mortality based on

632 random forest regression models for birds (a) and mammals (b). Boxplots show results for the

63315 imputed datasets for each taxonomic group. Study predictors (representing study site

634 coordinates and survey sampling frequency) are in bold, taxonomic predictor (order) is in

635 italics, traits with $<50 \%$ empirical data are marked with an asterisk. 


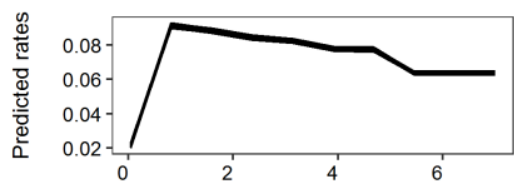

Survey interval (d)
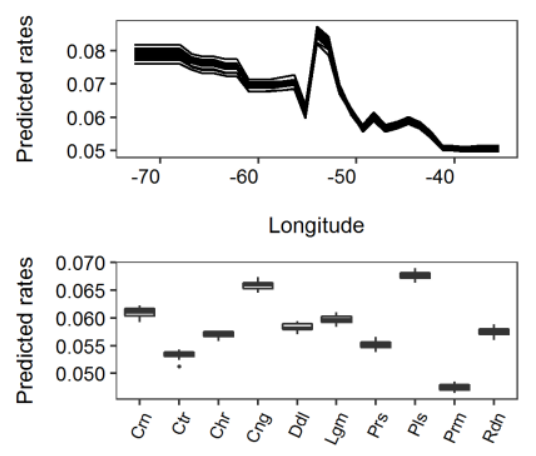

Taxonomic order

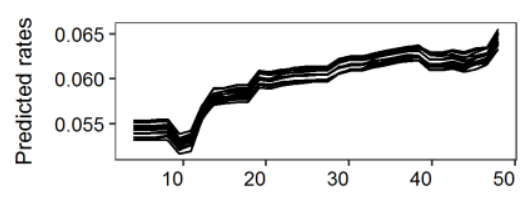

Habitat breadth

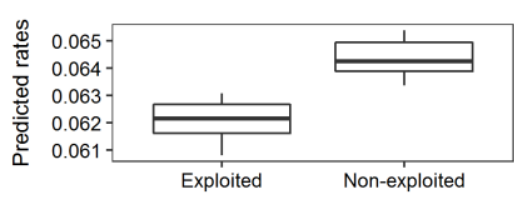

Direct exploitation

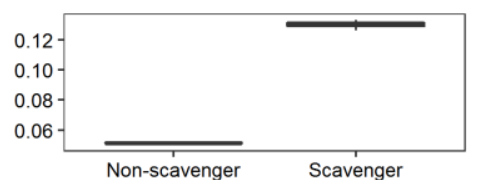

Scavenger

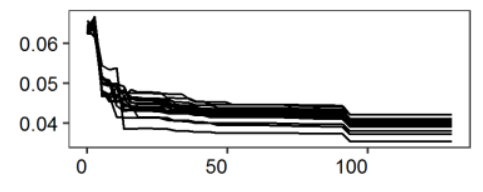

Home range size $(\mathrm{km} 2)$

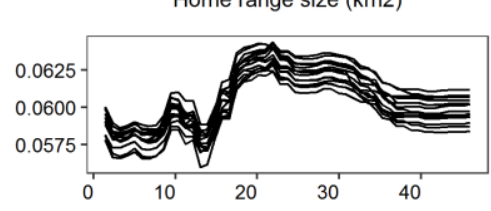

Lifespan (yrs)

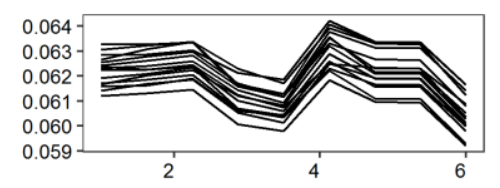

Diet breadth

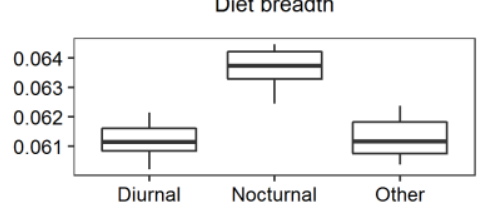

Activity time

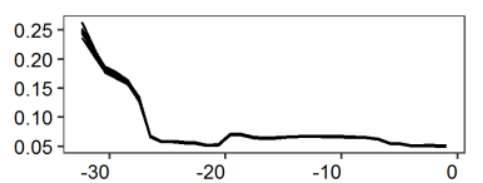

Latitude
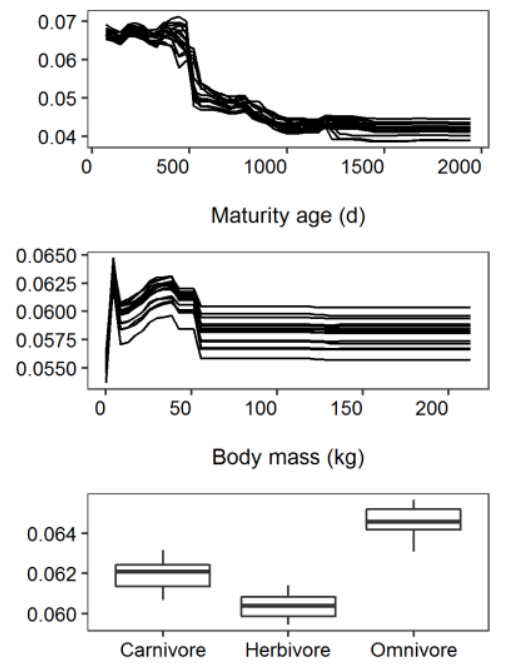

Trophic level

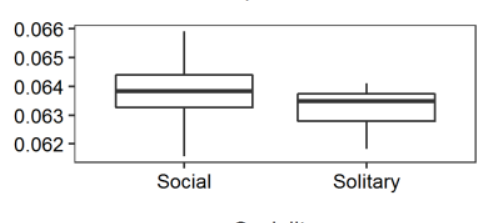

Sociality

638 Figure 2. Partial dependence plots for all tested predictors on the predicted road mortality

639 rates of Brazilian birds. Predictors are in descending variable importance order (see Fig. 1a).

640 Showing results for the 15 imputed datasets. Note that y-scales differ among plots.

641 Taxonomic orders are abbreviated as follows: Acc (Accipitriformes), Ans (Anseriformes), Ccl

642 (Cuculiformes), Chr (Charadriiformes), Clm (Columbiformes), Cpr (Caprimulgiformes), Crc

643 (Coraciiformes), Crm (Cariamiformes), Cth (Cathartiformes), Flc (Falconiformes), Gll

644 (Galliformes), Grf (Gruiformes), Pcf (Piciformes), Plc (Pelecaniformes), Pss (Passeriformes),

645 Pst (Psittaciformes), Slf (Suliformes), Strg (Strigiformes), Strt (Struthioniformes). 

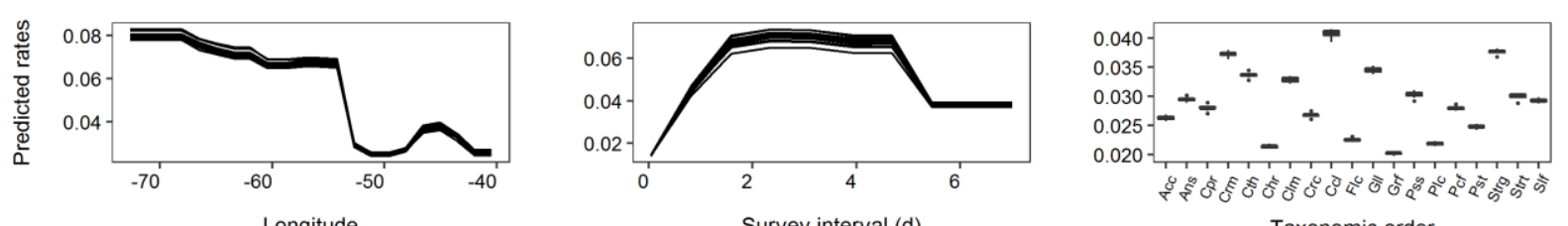

Survey interval (d)
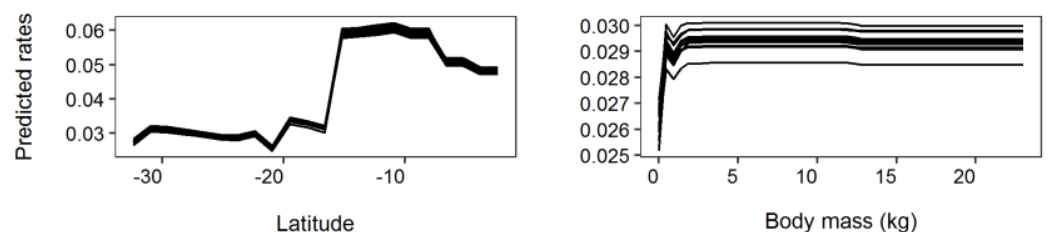

Taxonomic order
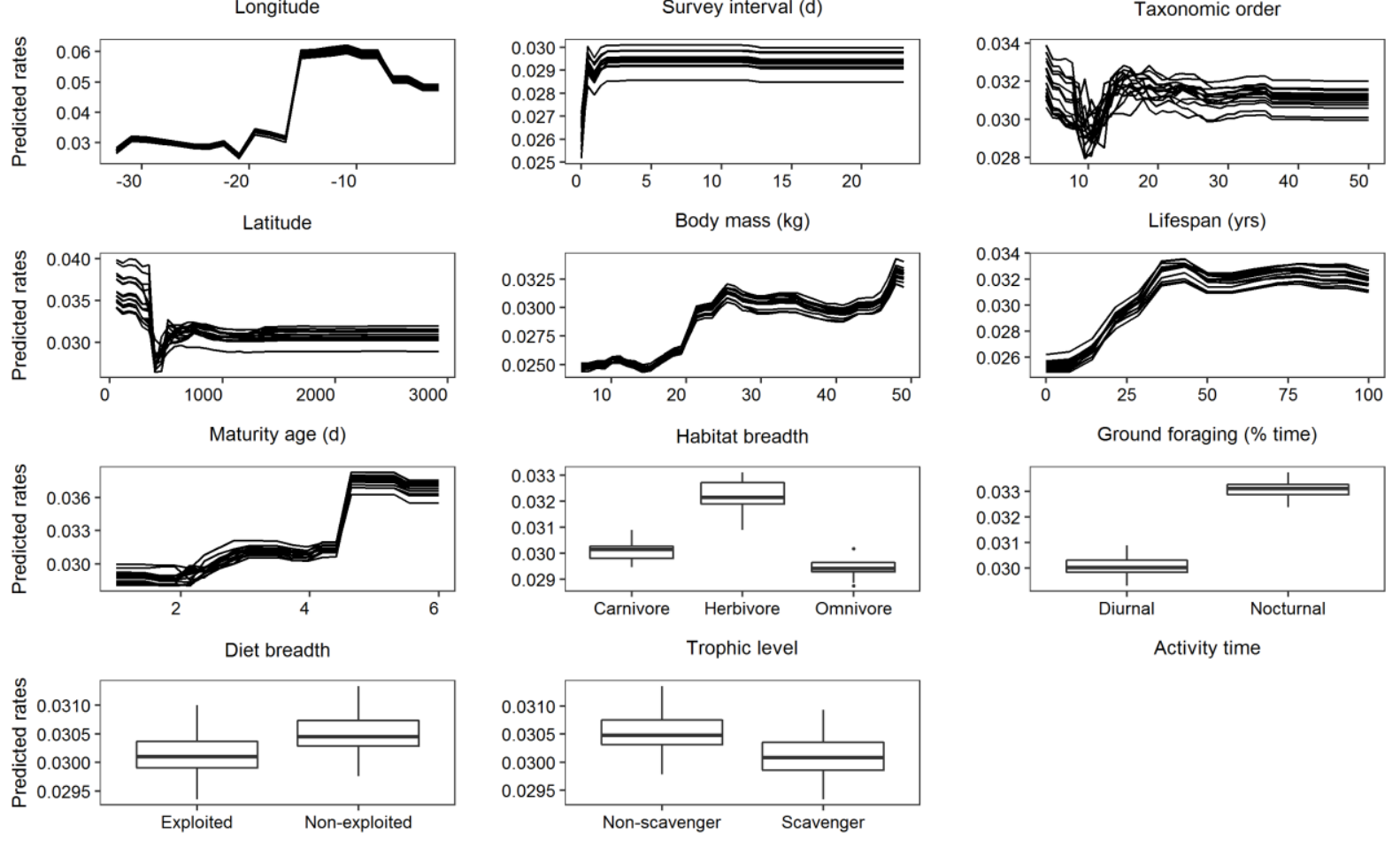

Activity time

649 Figure 3. Partial dependence plots for all tested predictors on the predicted road mortality

650 rates of Brazilian mammals. Predictors are in descending variable importance order (see Fig.

651 1b). Showing results for the 15 imputed datasets. Note that y-scales differ among plots.

652 Taxonomic orders are abbreviated as follows: Crn (Carnivora), Ctr (Cetartiodactyla), Chr

653 (Chiroptera), Cng (Cingulata), Ddl (Didelphimorphia), Lgm (Lagomorpha), Prs

654 (Perissodactyla), Pls (Pilosa), Prm (Primates), Rdn (Rodentia). 

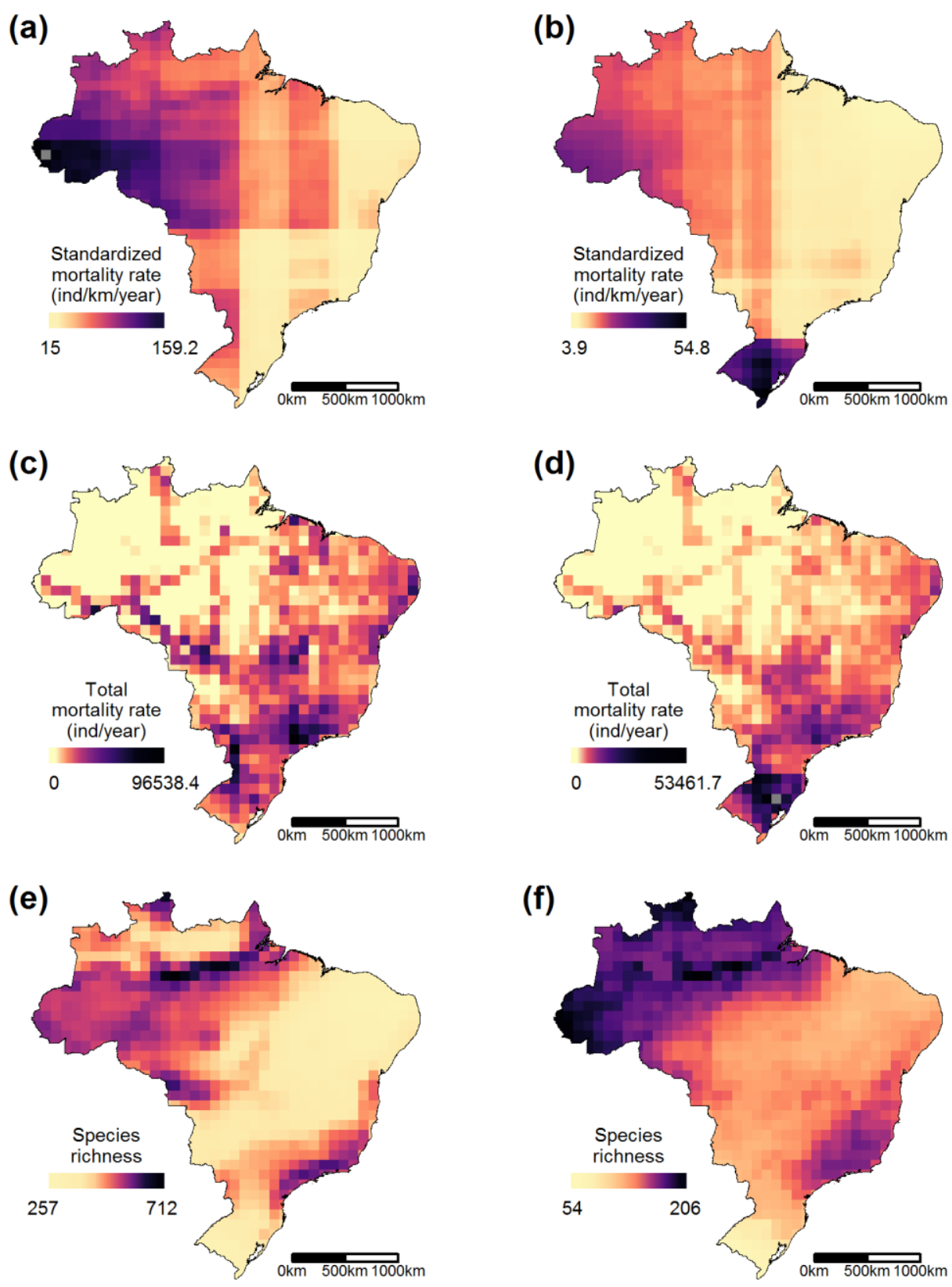

657 Figure 4. Predicted standardized road mortality rates (in ind/km/year) for birds (a) and

658 mammals (b) in Brazil. Total road mortality rates based on existing paved roads (ind/year) for 659 birds (c) and mammals (d). Total bird (e) and mammalian (f) species richness. 
661 Supplementary information for González-Suárez, M; Zanchetta Ferreira, F; Grilo, C.

662 Spatial and species-level predictions of road mortality risk using trait data. Global Ecology

663 and Biogeography

664 [Appendices S1-S3]

665

666 Appendix S1. Correction of mortality rates

667

668 We used a correction factor derived from estimates of carcass persistence described in Santos,

669 Carvalho, \& Mira (2011). They estimated persistence probability $(S)$, which we converted into

670 a correction factor $=1+(1-S)$ adapting their estimates for survey intervals of 1,2 and 7 days to

671 our observed ranges, and combining some species groups to match our data (Table S1.1).

672 Estimates from studies with survey intervals < 1 day (ranging from twice a day to 16 times a

673 day) were not corrected. Body mass was given priority when defining groups (e.g. rates for a

674 bird of prey of $130 \mathrm{~g}$ were corrected based on the "Small birds" factor).

\begin{tabular}{lrrr}
\hline Groups & \multicolumn{3}{c}{ Survey intervals } \\
\cline { 2 - 3 } & $1.0-1.4$ & $1.5-3.0$ & $3.0-7.0$ \\
\hline Small birds (4-200 g) & 1.634 & 1.797 & 1.968 \\
\hline Large birds (200-23000 g, excluding birds of prey) & 1.283 & 1.391 & 1.717 \\
\hline Birds of prey (175-1600 g) & 1.255 & 1.327 & 1.555 \\
\hline Small mammals (29-300 g) & 1.611 & 1.759 & 1.970 \\
\hline Large mammals (1100-170000 g) & 1.196 & 1.294 & 1.457 \\
\hline Bats (20-60 g) & 1.854 & 1.963 & 2.000
\end{tabular}


(a)

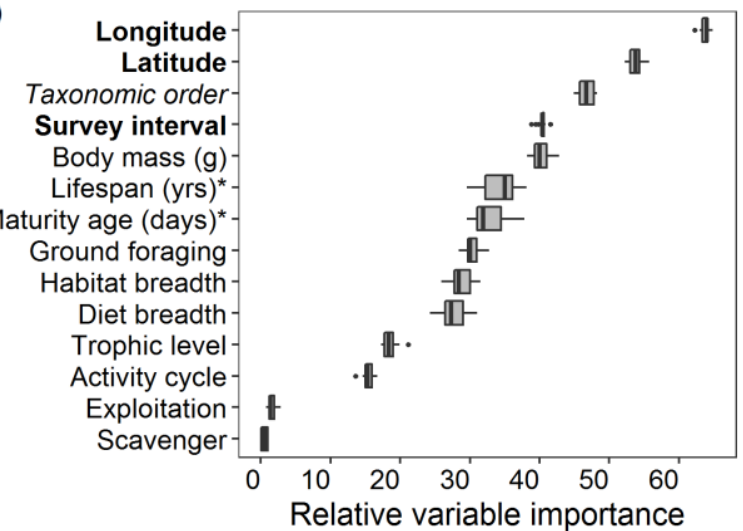

(b)

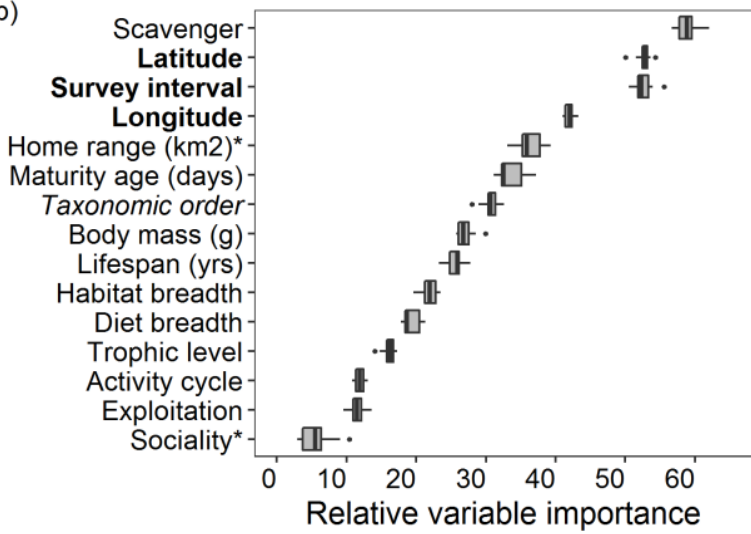

681 Figure S2.1. Relative importance of predictors associated with empirical uncorrected road

682 mortality based on random forest regression models for bird (a) and mammal (b). Boxplots

683 show results for the 15 imputed datasets for each taxonomic group. Study predictors

684 (representing study site coordinates and survey sampling frequency) are in bold, taxonomic

685 predictor (order) is in italics, traits with $<50 \%$ empirical data are marked with an asterisk.

686
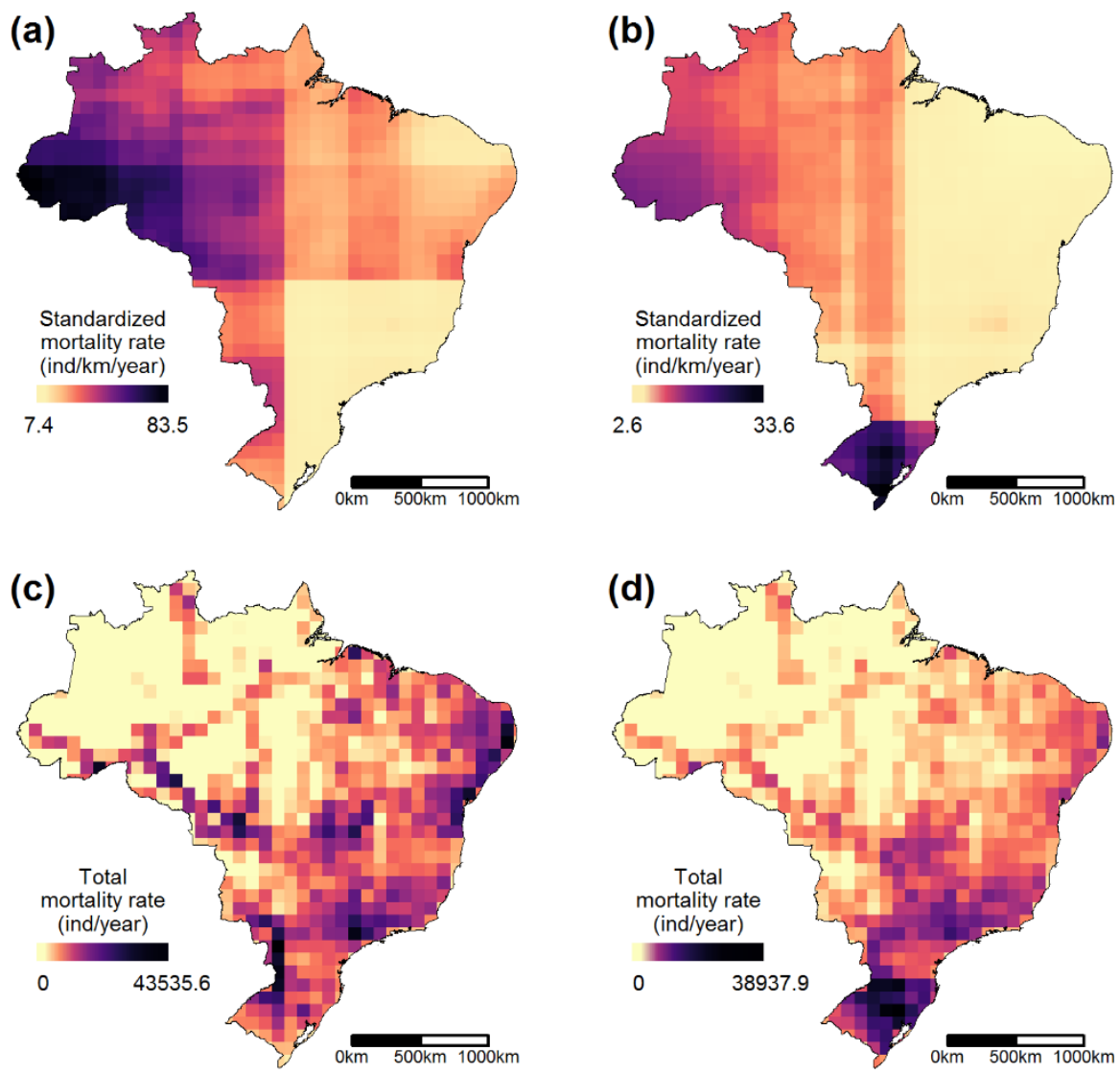
688 Figure S2.2. Predicted standardized road mortality rates (in ind/km/year) for birds (a) and mammals (b) in Brazil. Total road mortality rates based on existing paved roads (ind/year) for

690 birds (c) and mammals (d). Values based on models fitted for uncorrected road-kill rates.

691
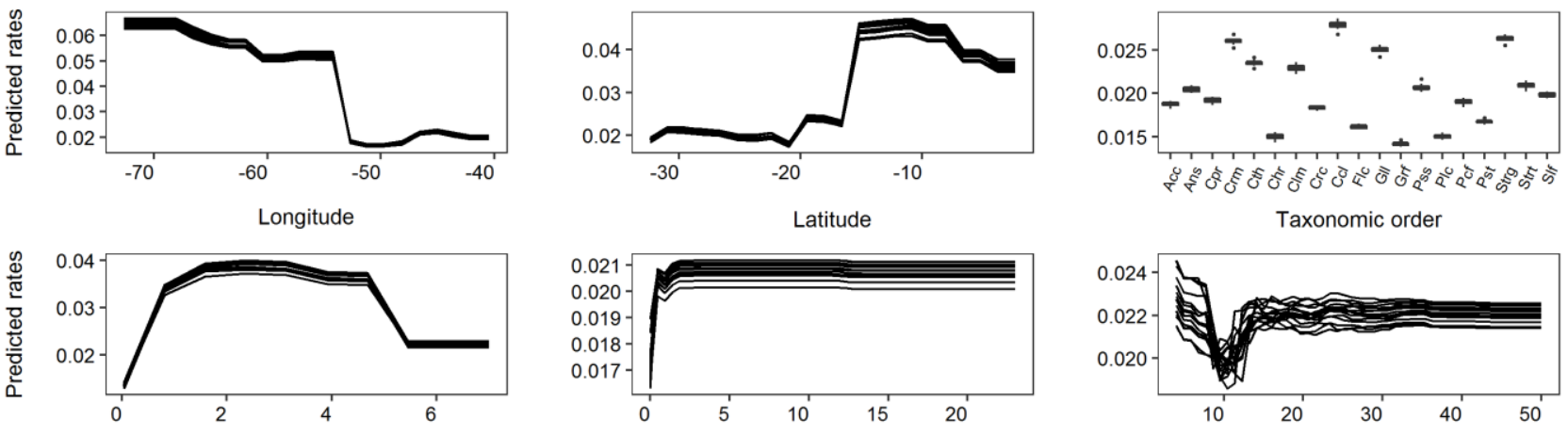

Latitude Taxonomic order
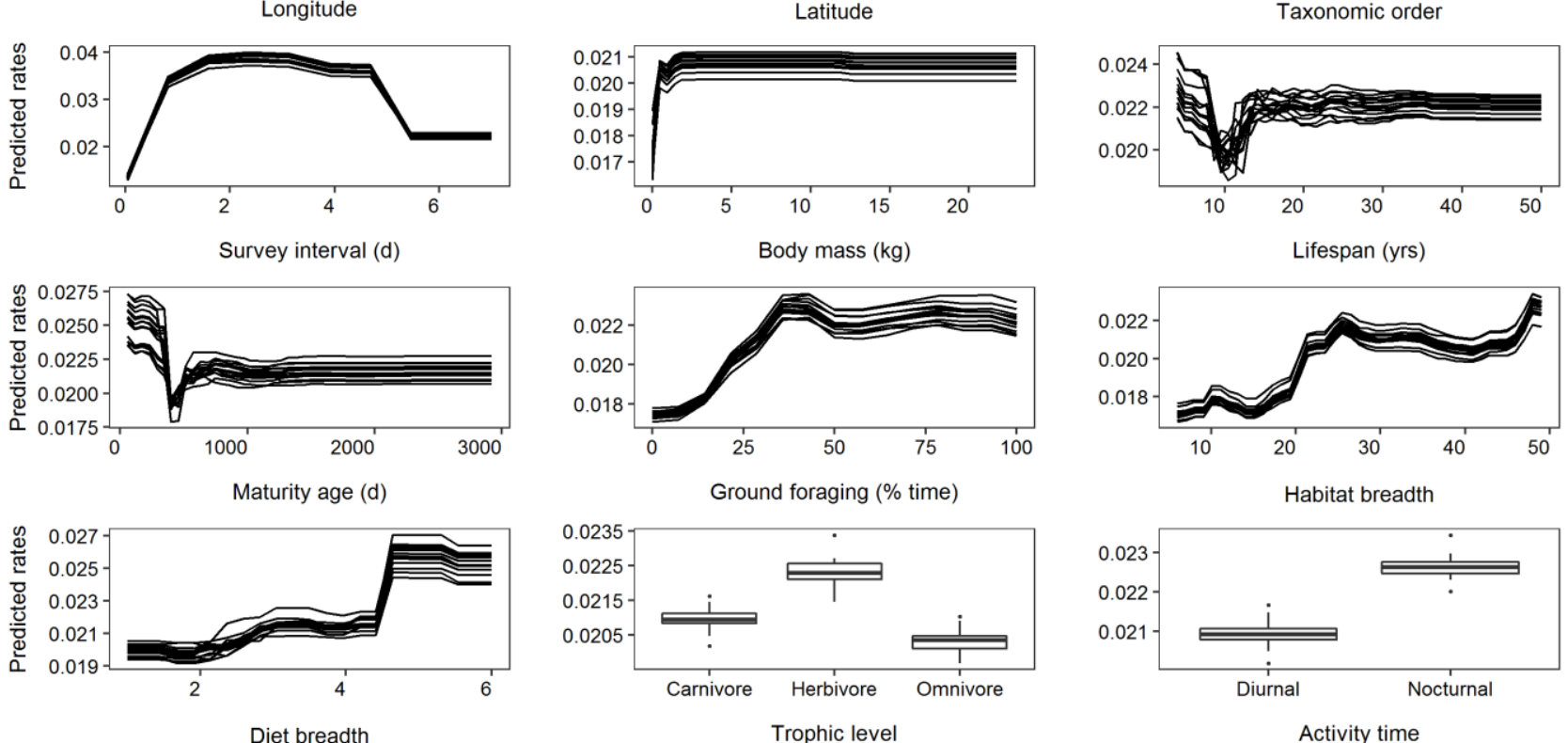

692

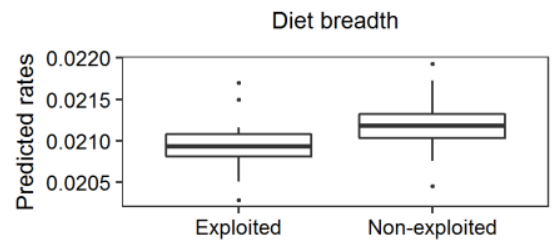

693

Direct exploitation

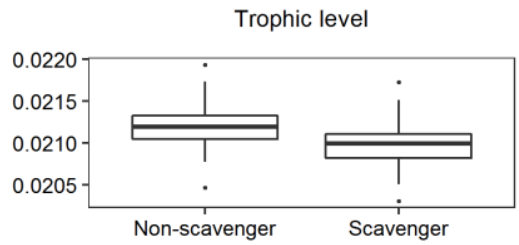

Activity time

694 road mortality rates of Brazilian birds. Rates are in ind/km/year. Predictors are in descending

695 variable importance order (Fig. S2.1). Showing results for the 15 imputed datasets. Note that

$696 \mathrm{y}$-scales differ among plots. Taxonomic orders are abbreviated as follows: Acc

697 (Accipitriformes), Ans (Anseriformes), $\mathrm{Ccl}$ (Cuculiformes), Chr (Charadriiformes), Clm

698 (Columbiformes), Cpr (Caprimulgiformes), Crc (Coraciiformes), Crm (Cariamiformes), Cth

699 (Cathartiformes), Flc (Falconiformes), Gll (Galliformes), Grf (Gruiformes), Pcf (Piciformes),

700 Plc (Pelecaniformes), Pss (Passeriformes), Pst (Psittaciformes), Slf (Suliformes), Strg

701 (Strigiformes), Strt (Struthioniformes). 

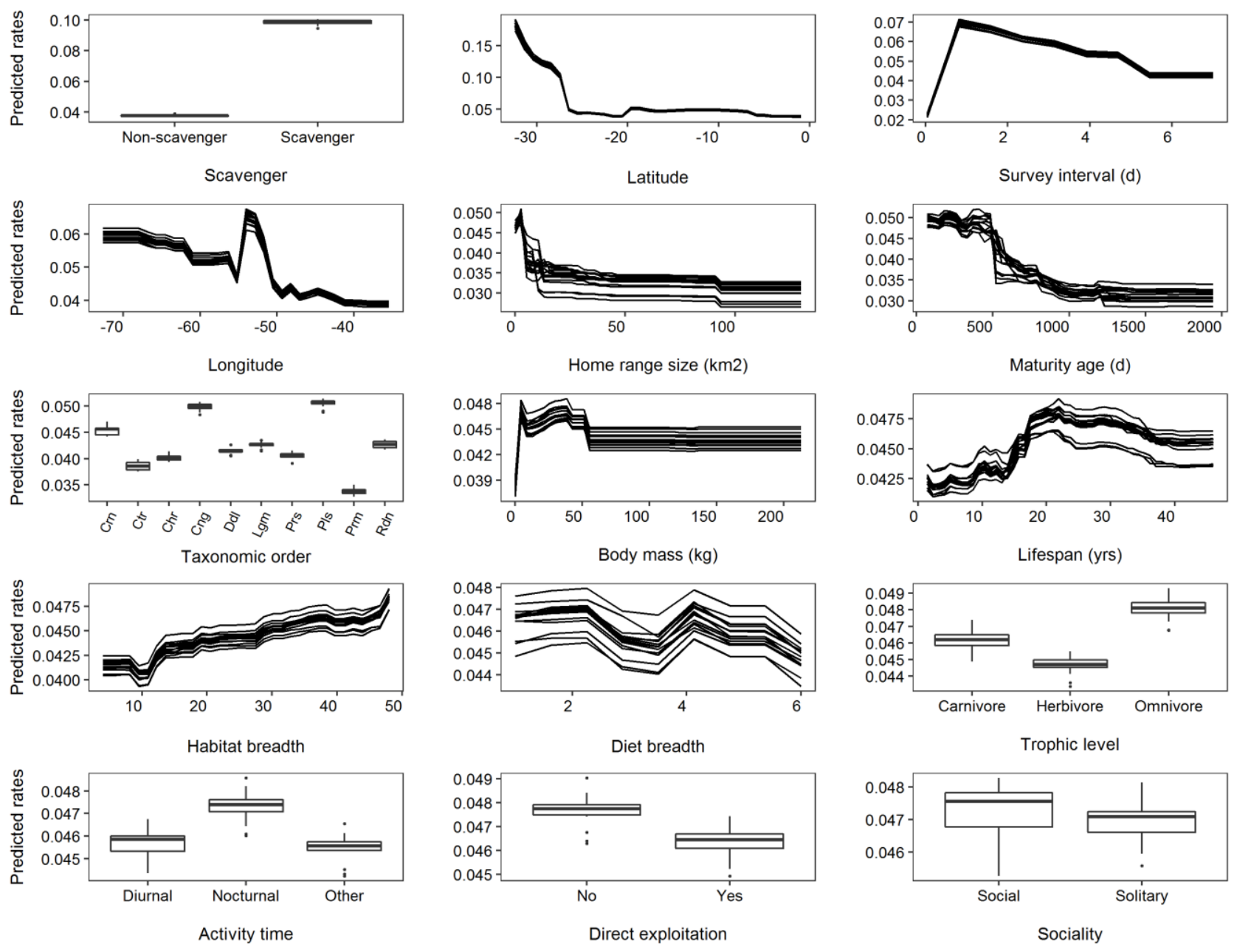

704 Figure S2.4. Partial dependence plots for all tested predictors on the predicted uncorrected

705 road mortality rates of Brazilian mammals. Predictors are in descending variable importance

706 order (Fig. S2.1). Showing results for the 15 imputed datasets. Note that y-scales differ among

707 plots. Taxonomic orders are abbreviated as follows: Crn (Carnivora), Ctr (Cetartiodactyla),

708 Chr (Chiroptera), Cng (Cingulata), Ddl (Didelphimorphia), Lgm (Lagomorpha), Prs

709 (Perissodactyla), Pls (Pilosa), Prm (Primates), Rdn (Rodentia). 
711
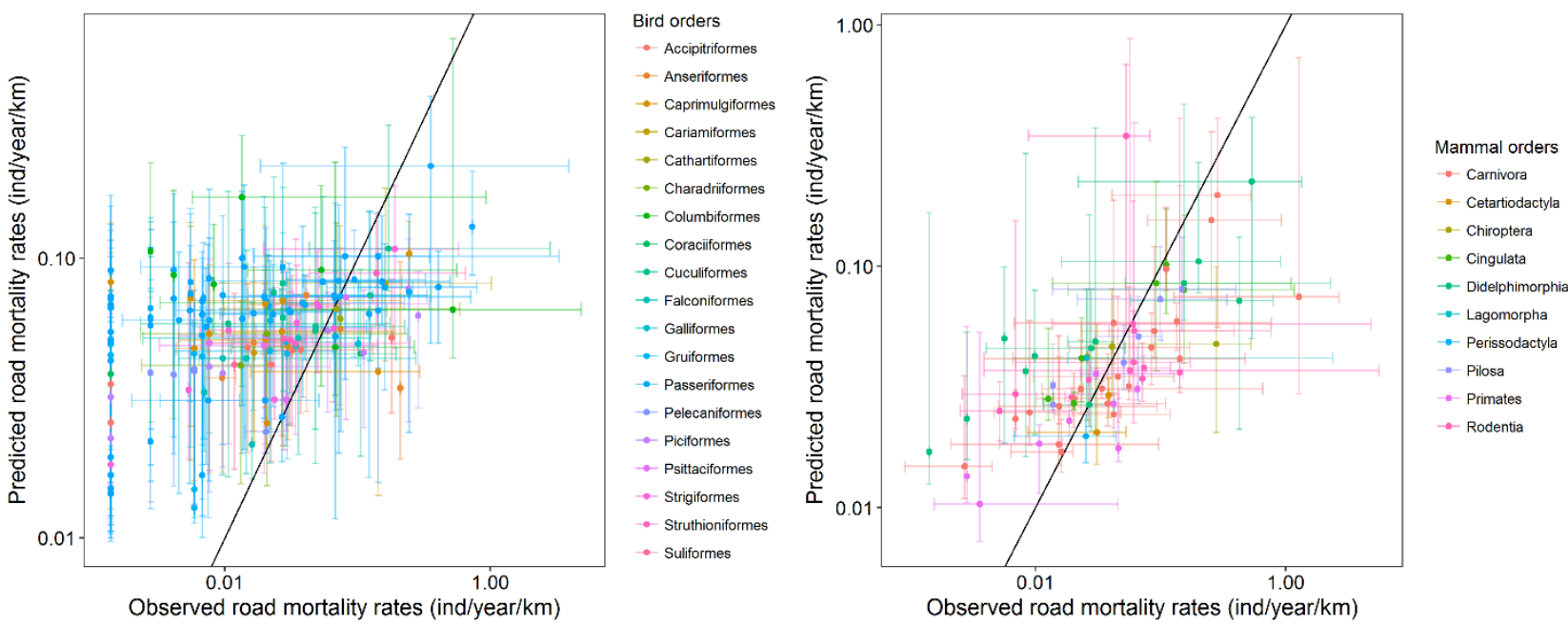

713 Figure S2.5. Predicted and observed uncorrected road mortality rates for 170 species of birds

714 and 74 mammals. Symbol is the median value from all surveys for empirical data and across

715 all predicted locations - grid cells, for predicted rates. Error bars represent the minimum and

716 maximum range in observed and predicted values. Diagonal line indicates the 1:1

717 relationship. 


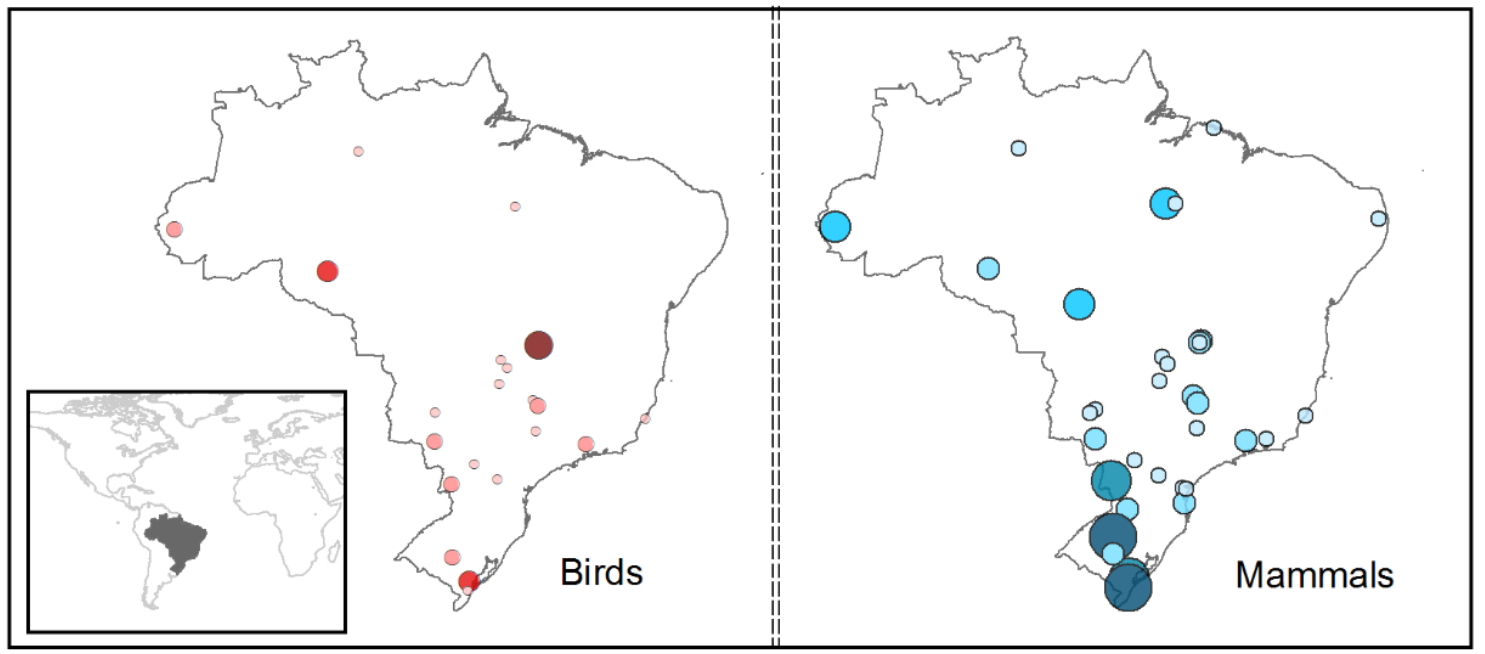

721 Figure S3.1. Location of the surveyed roads in Brazil represented in the 41 studies with road

722 mortality data for birds and mammals (note that some studies provided mortality rates for

723 both groups). The size of the symbols represent the median road mortality rates for each

724 taxonomic group. In birds the values range from 0.001 to $1.68 \mathrm{ind} / \mathrm{km} /$ year, while in

725 mammals values range from 0.003 to $18.5 \mathrm{ind} / \mathrm{km} / \mathrm{year}$. 
(a)

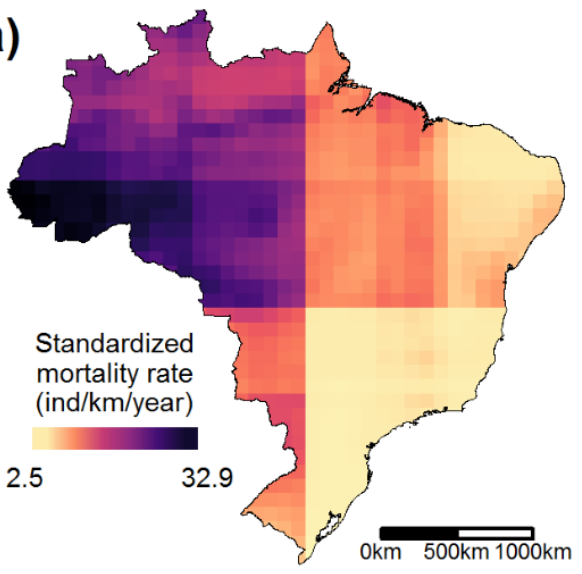

(c)

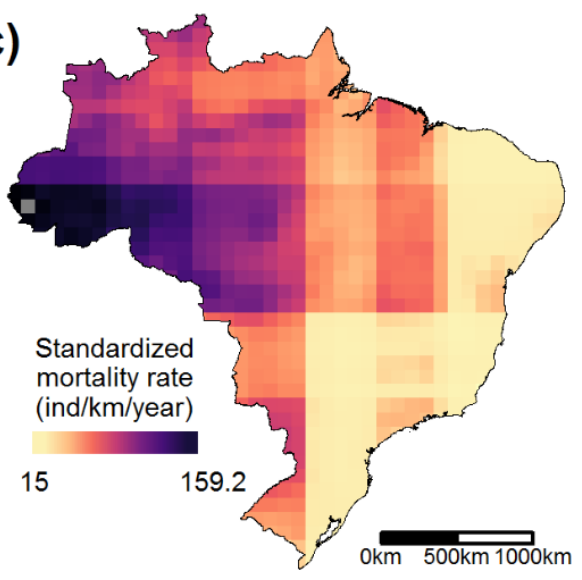

(e)

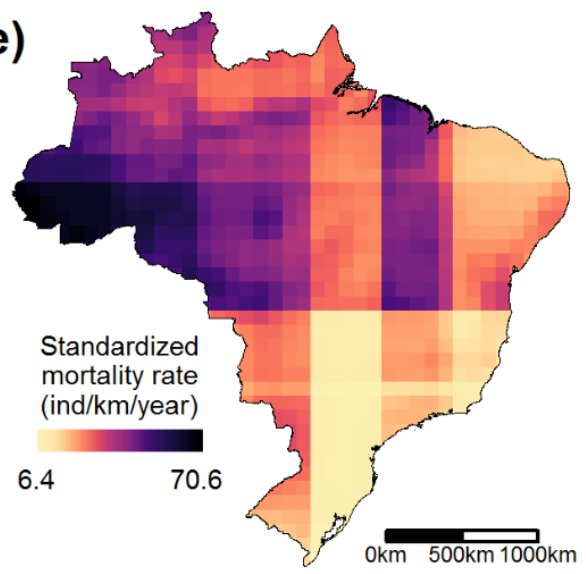

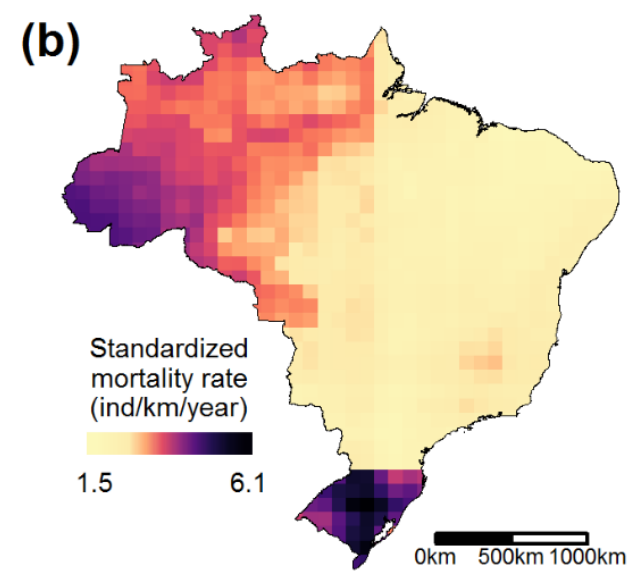

(d)

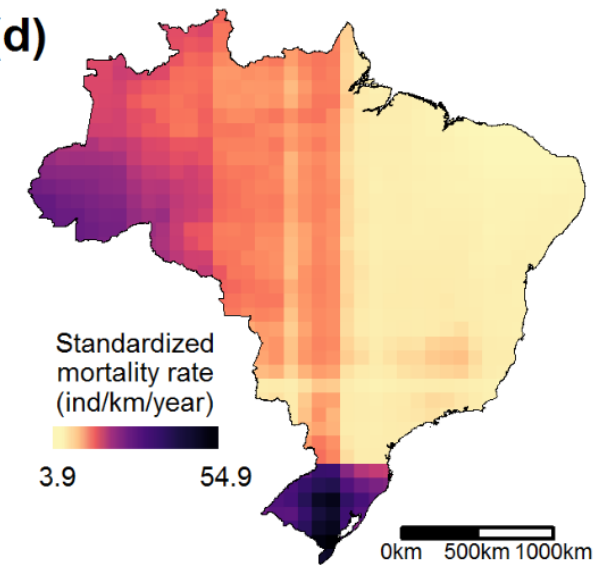

(f)

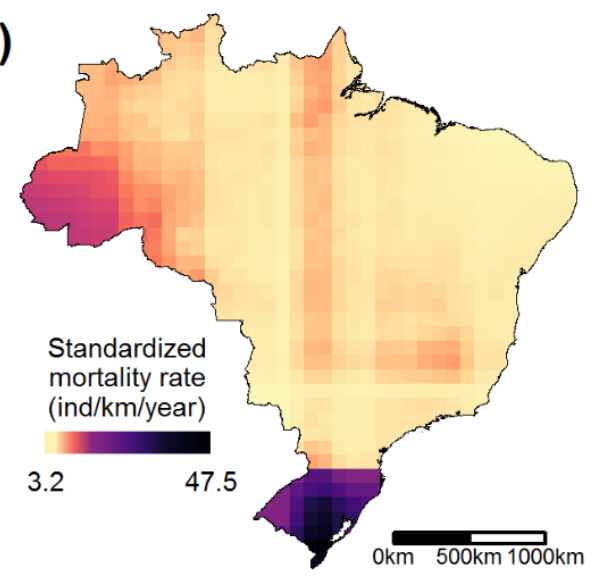

727 Figure S3.2. Predicted standardized road mortality rates (in ind/km/year) in Brazil assuming

728 the minimum observed survey interval [(a) birds, (b) mammals, both 0.0417 days between

729 surveys], mean observed interval [(c) birds 3.40 days between surveys, (d) mammals 3.64

730 days between surveys], and maximum observed interval [(e) birds, (f) mammals, both 7 days

731 between surveys, which was the maximum interval we considered for our study). 

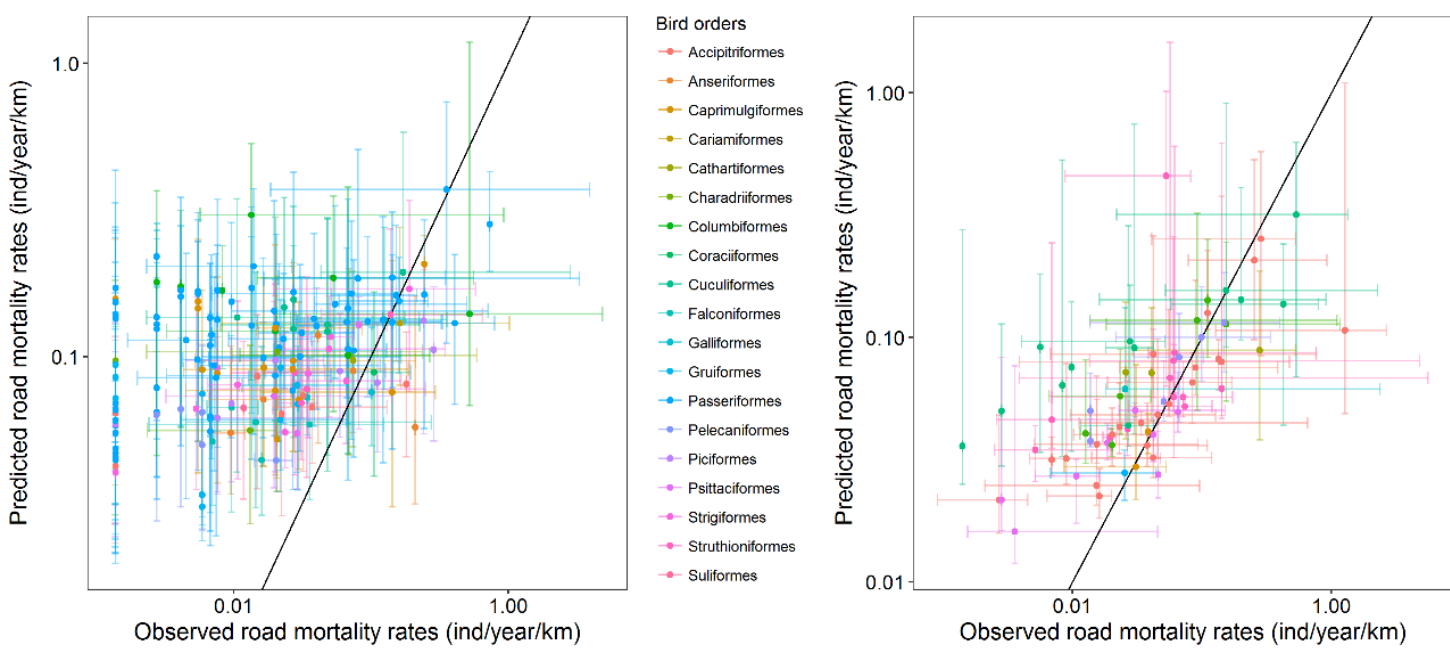

Mammal orders

$\rightarrow-$ Carnivora

- Cetartiodactyla

- Chiropter

- Cingulata

- Didelphimorphia

- Lagomorpha

- Perissodactyla

- Pilosa

$\rightarrow$ Primates

- Rodentia

Observed road mortality rates (ind $/$ year $/ \mathrm{km}$ )

Observed road mortality rates (ind $/$ year $/ \mathrm{km}$ )

734 Figure S3.3. Predicted and observed road mortality rates for 170 species of birds and 74

735 mammals. Symbol is the median value from all surveys for empirical data and across all

736 predicted locations - grid cells, for predicted rates. Error bars represent the minimum and

737 maximum range in observed and predicted values. Diagonal line indicates the 1:1

738 relationship.

739

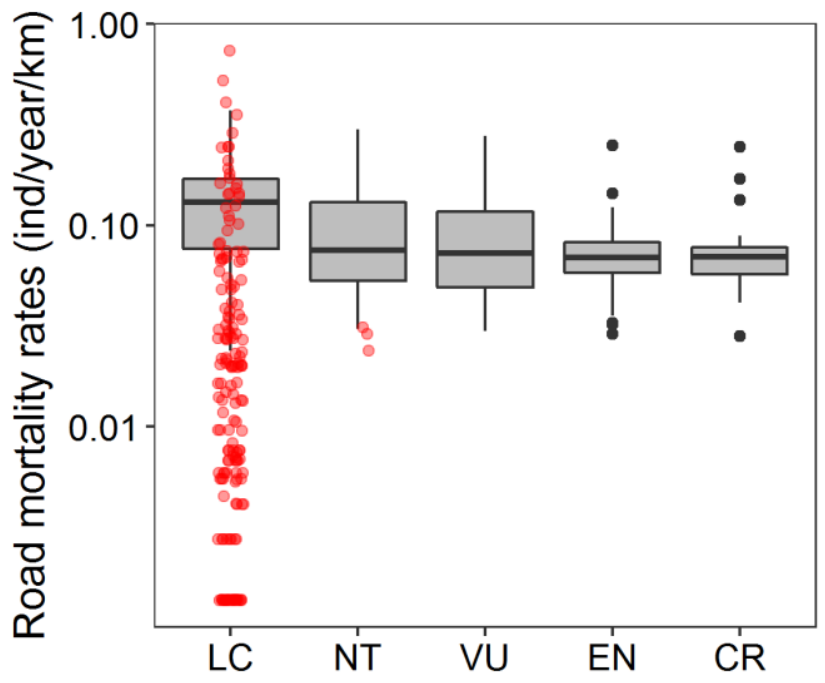

Red List Status

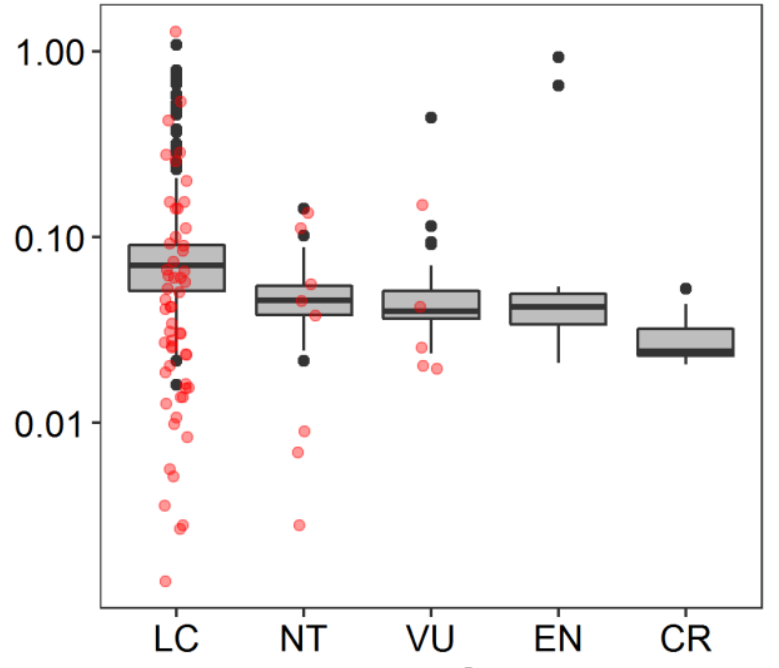

Red List Status

741 Figure S3.4. Median predicted (grey boxplot) and observed (red symbols) road mortality rates

742 for birds (left panel) and mammals (right panel) classified in the different IUCN Red List

743 status categories. 

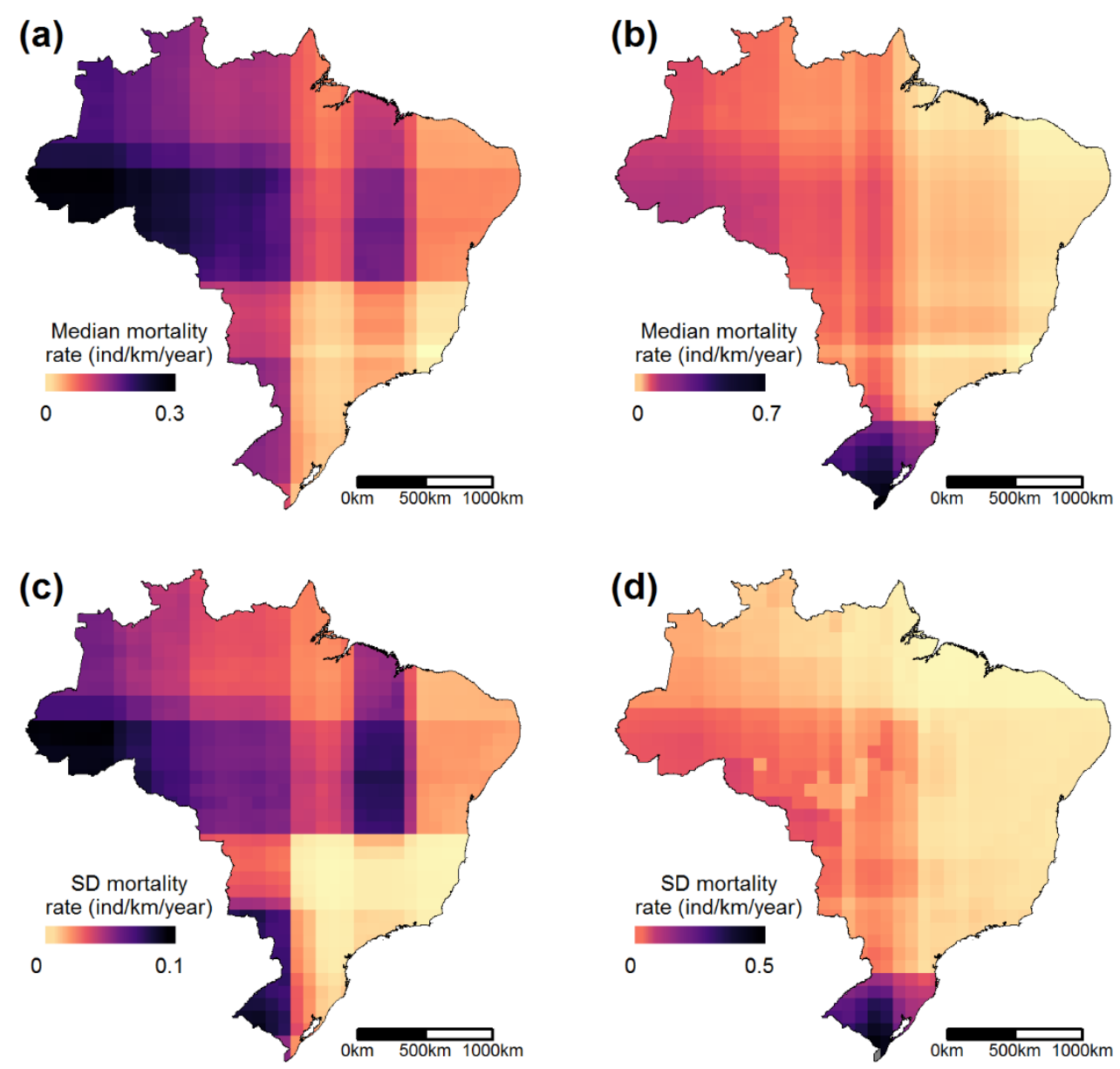

745 Figure S3.5. Predicted standardized road mortality rates (in ind/km/year) for birds [(a) median 746 rates, (c) standard deviation among species within each cell] and mammals [(a) median rates,

747 (c) standard deviation among species within each cell] in Brazil.
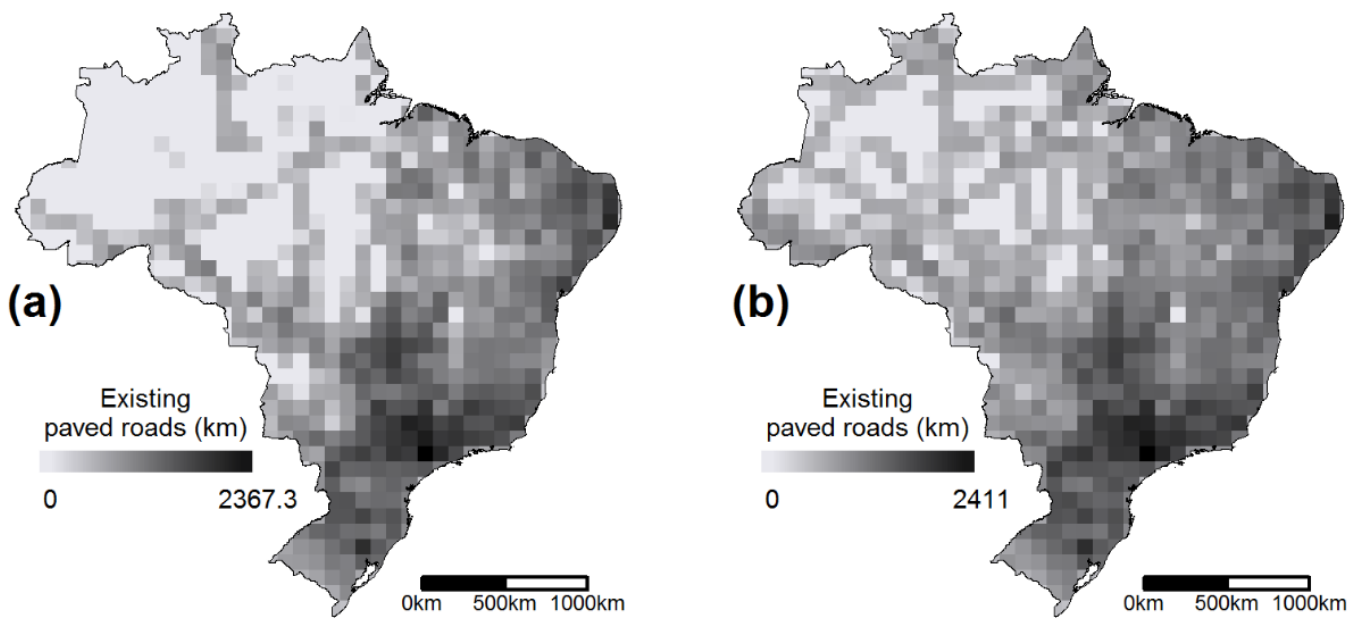
749 Figure 3.6. Road density map for Brazil reflecting current paved roads (panel a) and current 750 and planned paved roads (b). Road data from https://www.openstreetmap.org.

751
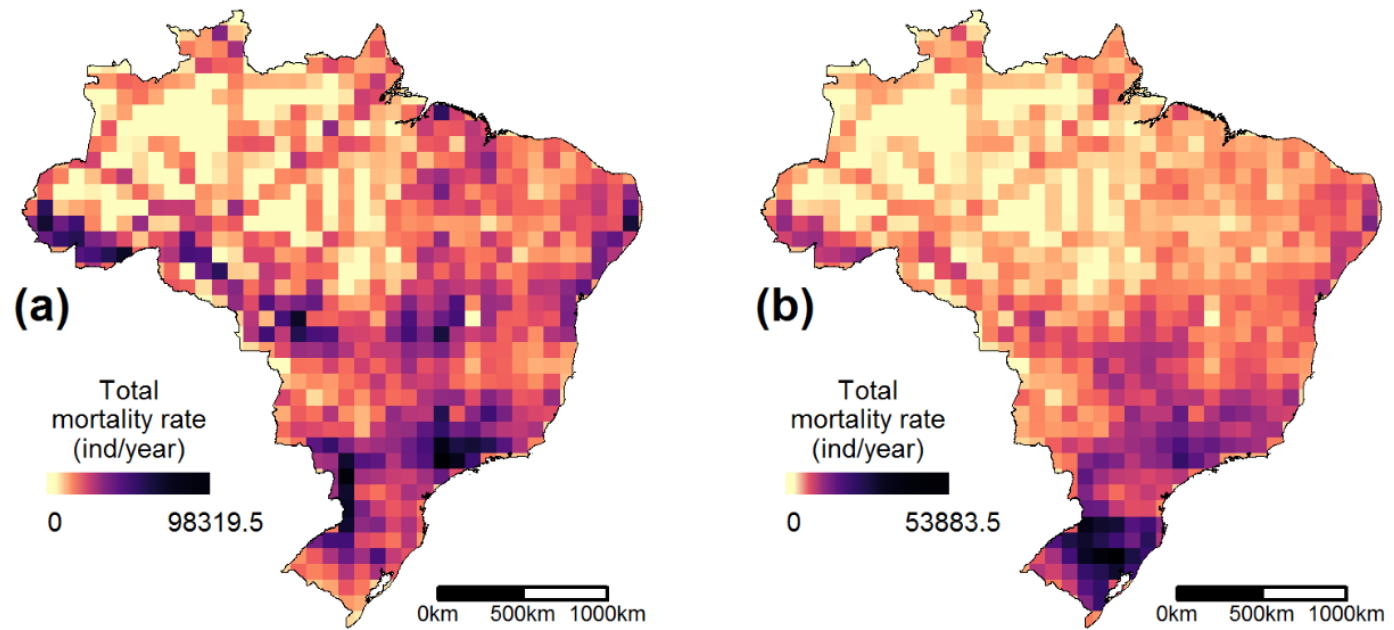

752

753 Figure S3.7. Predicted total road mortality rates (in ind/year) for birds (a) and mammals (b)

754 given the existing and planned paved road network in Brazil. Road data from

755 https://www.openstreetmap.org.

756

757

758 
(a)

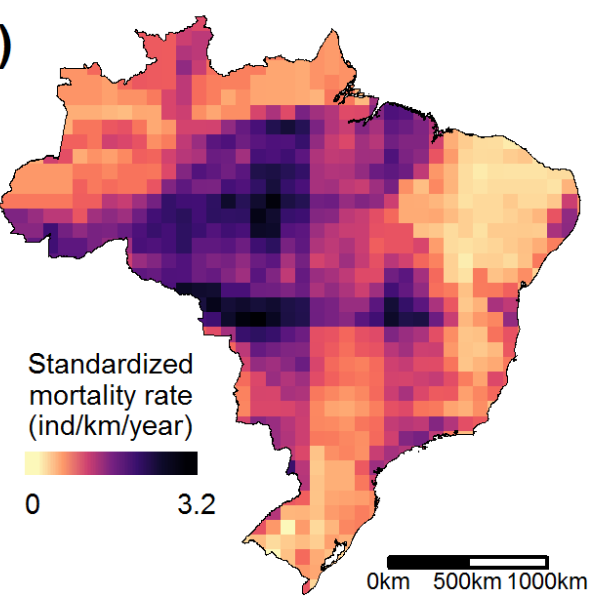

(c)

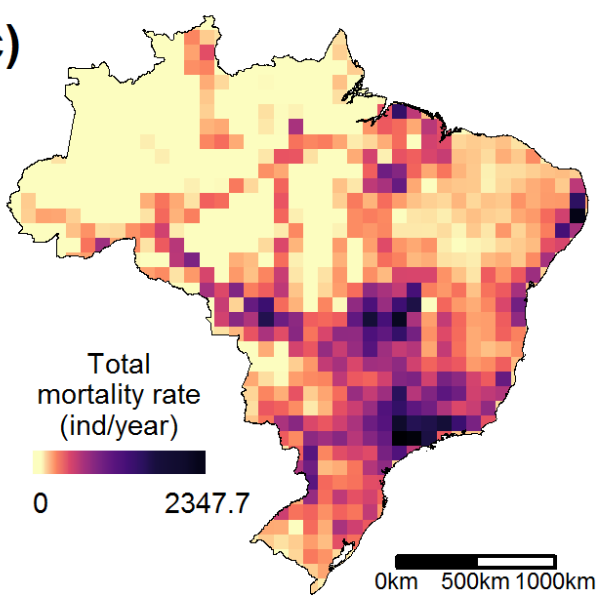

(e)

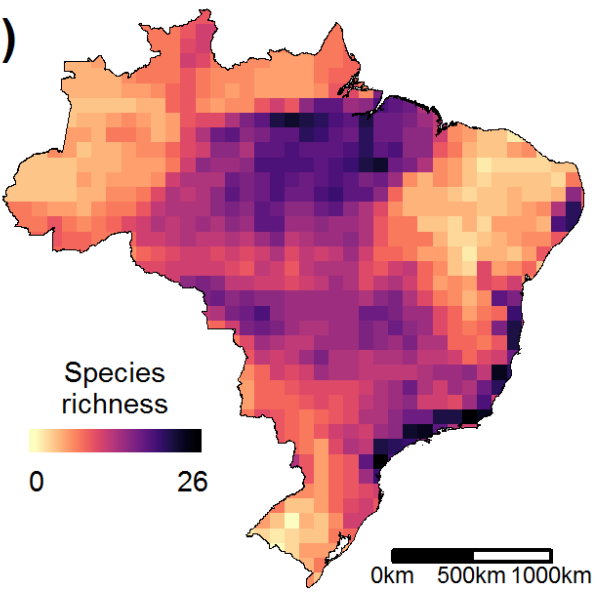

(b)

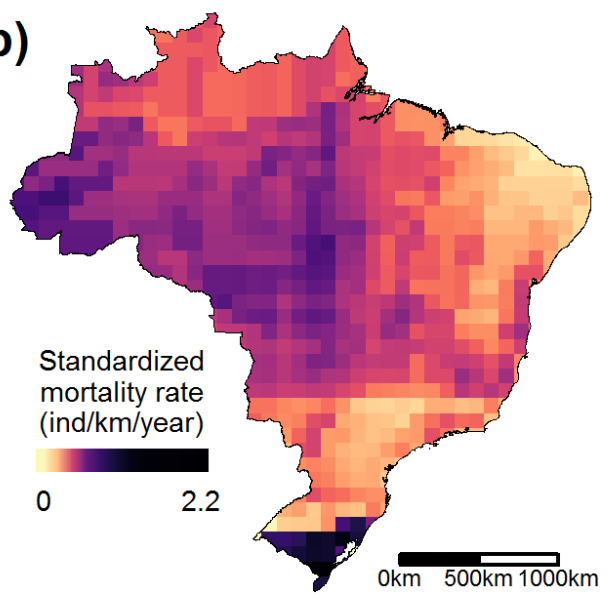

(d)

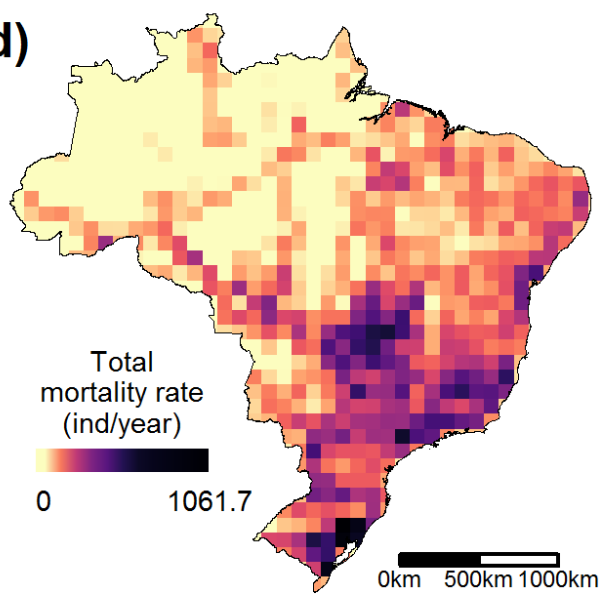

(f)

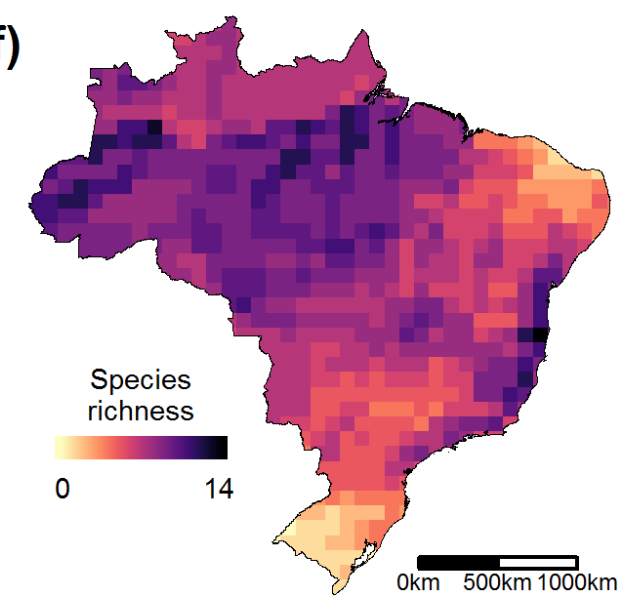

760 Figure S3.8. Predicted standardized road mortality rates (in ind/km/year) for threatened birds

761 (a) and threatened mammals (b) in Brazil. Total road mortality rates based on existing paved

762 roads (ind/year) for threatened birds (c) and threatened mammals (d). Total threatened bird (e)

763 and threatened mammalian (f) species richness. 